\title{
A dual function for Munc-18 in exocytosis of PC12 cells
}

\author{
Dagmar Schütz, ${ }^{1}$ Felipe Zilly, ${ }^{1}$ Thorsten Lang, ${ }^{1}$ Reinhard Jahn ${ }^{1}$ and Dieter Bruns,,${ }^{1,2}$ \\ ${ }^{1}$ Max-Planck-Institute for Biophysical Chemistry, Department of Neurobiology, Am Fassberg 11, 37077 Göttingen, Germany \\ ${ }^{2}$ University of Saarland, Institute for Physiology, Department of Molecular Physiology, Kirrbergerstraße 8, 66421 Homburg/Saar, \\ Germany
}

Keywords: amperometry, fusion pore, Mint1, neurotransmitter release, syntaxin

\begin{abstract}
Munc-18 interacts with the SNARE protein syntaxin and is supposed to influence transmitter release by controlling the formation of exocytosis-relevant SNARE complexes. Here, we used combined biochemical and physiological analyses to study the role of the Munc-18/syntaxin interaction in large dense core vesicle (LDCV) exocytosis of neuroendocrine PC12 cells. We compared two Munc18 mutants carrying mutations in the syntaxin-binding region and show that Munc-18's membrane association depends on direct binding to syntaxin. The data suggest that perturbation of syntaxin binding inhibits neurotransmitter release upstream of the individual fusion event implying an essential role of the Munc-18/syntaxin complex leading to exocytosis. Furthermore, we show that a Munc18 mutant lacking any syntaxin binding has a stimulatory effect on secretion, and provide evidence that the Munc-18/Mint1 interaction may constitute a second pathway for Munc-18 to regulate exocytosis. We propose that Munc-18 represents a dynamic link between syntaxin-related and Mint1-related mechanisms, both involved in the control of LDCV exocytosis in neuroendocrine cells.
\end{abstract}

\section{Introduction}

Sec1/Munc-18 proteins (referred to as SM proteins) comprise a family of highly conserved proteins that are essential for membrane fusion, but their role in exocytosis is little understood (reviewed by Jahn, 2000; Rizo \& Südhof, 2002; Gallwitz \& Jahn, 2003; Toonen \& Verhage, 2003). In neurons, the lack of Munc-18 causes a complete block of synaptic transmission (Verhage et al., 2000; Weimer et al., 2003), whereas increased levels of the homologue protein rop at the Drosophila neuromuscular junction lead to a reduction in neurotransmitter release (Harrison et al., 1994; Schulze et al., 1994). Experiments with neuroendocrine cells, however, revealed a picture in which the functional consequences of changing expression levels of Munc18 are complementary. Here, calcium-dependent exocytosis is strongly diminished in the absence of Munc-18 and is stimulated when protein levels are increased by overexpression (Voets et al., 2001).

Munc-18 was first identified in the brain by its ability to bind to the plasma membrane protein syntaxin1 with high affinity (Hata et al., 1993; Garcia et al., 1994; Pevsner et al., 1994a). Syntaxin1 forms a ternary complex with SNAP-25 on the plasma membrane and with synaptobrevin II residing on the vesicular membrane. These proteins (also referred to as soluble $N$-ethylmaleimide-sensitive fusion protein attachment protein (SNAP) receptor or SNARE proteins) contain heptad repeat regions, named SNARE motifs, that can assemble into helical bundles involving coiled coil interactions, also referred to as core complexes. It is assumed that the membrane-bridging interactions between SNARE proteins lead to formation of ternary trans-SNARE complexes (between opposing membranes) that pull vesicular and plasma membrane in close apposition causing membrane fusion and subsequently neurotransmitter release (Hanson et al., 1997; Brunger, 2001; Chen \& Scheller, 2001). Biochemical studies show that binding

Correspondence: Dr D. Bruns, ${ }^{2}$ University of Saarland, as above.

E-mail: dieter.bruns@uniklinik-saarland.de

Received 21 December 2004, revised 25 February 2005, accepted 1 March 2005 of Munc-18 to syntaxin1 prevents syntaxin's association with the other SNARE partners (Pevsner et al., 1994b; Hayashi et al., 1995; Yang et al., 2000). This observation has been most influential in developing a conceptual framework for the role of SM proteins in exocytosis, employing them as inhibitors for the formation of exocytosis-relevant SNARE complexes. However, the finding that binding of an SM protein to syntaxin precludes ternary complex formation is not a general phenomenon (Gallwitz \& Jahn, 2003). For example, the yeast Seclp protein binds to the heterotrimeric complex composed of the corresponding SNARE homologues, Snc1p, Sec9p and Sso1p, but not to monomeric Sso1p, the yeast syntaxin homologue (Carr et al., 1999). Moreover, Sec1p concentrates at exocytotic sites and secretion is blocked in sec1 null mutants, suggesting an essential or catalytic rather than an inhibitory function in exocytosis. A current hypothesis, based on yeast genetics, is that an SM protein bound to syntaxin interacts with Rab GTPases during initial stages of vesicle target recognition (Tall et al., 1999) and dissociates from syntaxin to allow, or even to facilitate, the interaction of syntaxin with other SNAREs (Grote et al., 2000; Peng \& Gallwitz, 2002; for review see Gallwitz \& Jahn, 2003).

Besides syntaxin, Munc-18 interacts with a number of other proteins whose role in exocytosis is less well studied. For instance, Mint proteins (Munc-18 interacting proteins; Okamoto \& Sudhof, 1997) are multimodular adapter proteins that have been proposed to function in membrane transport and may define, in conjunction with other proteins, targeting sites for vesicle translocation (Butz et al., 1998; Setou et al., 2000). Furthermore, Munc- 18 is believed to interact with Doc $2 \alpha$ and Doc $2 \beta$, two synaptic proteins of unknown function that contain potentially calcium-binding C2-like domains (Verhage et al., 1997). It is not yet known if these proteins operate by controlling the interactions of SM proteins with syntaxins or if their binding to SM proteins involves separate pathways that are linked to exocytosis in a still unknown manner. Although the previous studies brought considerable insight into the function of Munc-18, a great deal remains to be learned about the molecular means by which it controls exocytosis. 
Here, we used combined biochemical and physiological analyses to elucidate the function of Munc-18 in secretion from neuroendocrine cells. For this, we introduced two mutations into the Munc-18 protein that reside within the syntaxin-binding region (Misura et al., 2000) and that have been shown to be lethal upon homotypic expression in Drosophila (Harrison et al., 1994; Wu et al., 1998). We analysed the capabilities of the mutant proteins to interact with the known binding partners and studied their effects on neurotransmitter release with carbon fibre amperometry upon overexpression in neuroendocrine PC12 cells. With a mutant showing a lowered affinity towards syntaxin we were aiming to perturb the endogenous Munc-18/syntaxin interaction and found an inhibition of large dense core vesicles (LDCV) exocytosis, suggesting that the Munc-18/syntaxin interaction facilitates rather than inhibits release. For a second mutant, showing a nearly complete disruption of syntaxin binding, a strong stimulatory effect on exocytosis is measured, indicating that non-syntaxin-related functions of Munc-18 also govern exocytosis. In addition, we found that overexpression of the cytosolic binding partner Mint1 influences neurotransmitter release pointing to the possibility that the action of Munc-18 via Mint1 provides an alternative route to regulate exocytosis. Our biochemical experiments show that Munc-18's association with membranes predominantly depends on direct binding to syntaxin and, furthermore, that Mint1 and syntaxin compete for binding to Munc-18 suggesting that alternating complex formation can occur upon relocation of Munc-18 from a membrane-bound state to a cytosolic state.

Together, our data suggest that Munc-18 governs multiple mechanisms as regulation of SNARE complex formation (via syntaxin binding) and vesicle transport (via Mint1 binding), moving Munc-18 to centre stage in the control of the exocytotic response.

\section{Materials and methods}

\section{Materials}

Syntaxin1a cDNA was provided by R.H. Scheller. The following monoclonal antibodies were used: anti-GDI (Synaptic Systems, Goettingen, Germany), anti-Munc-18 and anti-Mint1 antibody (BD Transduction Laboratories), anti-myc (ATCC). HPC-1 antibody was used for detection of syntaxin1 (Barnstable et al., 1985). Ionomycin was obtained from Calbiochem (Germany). Texas Red-labelled secondary antibodies were purchased from Jackson Dianova (Germany).

\section{Cloning}

Full-length and mutated coding sequences were amplified using the polymerase chain reaction (PCR, PFU polymerase, Stratagene, La Jolla, CA, USA). Munc-18 cDNAs were subcloned for bacterial expression into pGEX-4T1 (GST-fusion protein, Pharmacia) and pET28a (Hexa-His tagged fusion protein, Novagen), and for eukaryotic expression into pBOB5.1 (gift from Tom Hughes, Yale University, New Haven, CT, USA) that has a pCR 3.1 (Invitrogen) backbone with a modified multiple cloning site. Munc-18-D34N and Munc-18-R39C constructs were generated using the overlapping primer method by Higuchi et al. (1988). Rat full-length Doc $2 \alpha$ was amplified from a rat brain cDNA library (gift of N. Brose, Göttingen, Germany) using a PCR procedure described by Duncan et al. (2000), and was subcloned into pGEX-4T1. Primers used for cloning of full-length rat Doc $2 \alpha$ were: Doc2BamHI 5'-atc gga tcc atg agg ggc cgc agg ggc-3'; DocXhoI $5^{\prime}$-gcg ctc gag tca ggc caa cgg caa cgc-3'. The neuropeptide Y (NPY)EGFP construct was used as described in Lang et al. (2001). All subcloned nucleotide sequences were verified by sequencing.
Generation of recombinant fusion proteins and binding assays

Protein expression was performed in Escherichia coli BL21(DE3). Bacteria were grown to a density of $\mathrm{OD}_{600}=0.7$ at $37^{\circ} \mathrm{C}$, protein expression was induced with $0.2 \mathrm{mM}$ IPTG at $21{ }^{\circ} \mathrm{C}$, and incubation was continued for another 2-4 h. Proteins were purified by affinity chromatography using GSH Sepharose (Amersham Pharmacia Biotech) or $\mathrm{Ni}^{2+}-\mathrm{NTA}-$ Agarose (Qiagen) according to manufacturer's instructions, and dialysed against binding buffer (in $\mathrm{mM}$ ): $\mathrm{NaCl}, 150$; Tris, 20, pH 7.5; DTT, 1; EGTA, 1; 0.1\% Triton X-100. GST-Mint1 was further purified on a Superdex200 gel filtration column. Binding assays with recombinant proteins were performed as follows. Recombinant proteins (concentrations given in figure legends) were incubated for $2 \mathrm{~h}$ at $4{ }^{\circ} \mathrm{C}$ with gentle agitation. Column eluates were analysed for purity by sodium dodecyl sulphate-polyacrylamide gel electrophoresis (SDS-PAGE) and staining with Coomassie Blue. Aliquots of purified proteins were snap frozen and stored at $-80{ }^{\circ} \mathrm{C}$. For binding assays involving Doc $2 \alpha, 1.8 \mu \mathrm{M}$ GST-Doc $2 \alpha$ was incubated with $3 \mu \mathrm{M}$ Munc18. GSH beads were added and the incubation was continued for another $2 \mathrm{~h}$ at $4{ }^{\circ} \mathrm{C}$. Beads were collected by centrifugation (supernatants were separated), washed rapidly $(3 \times 2 \mathrm{~min} /$ wash $)$ with binding buffer and were resuspended in a volume matching that of the supernatant. Samples were analysed by SDS-PAGE, and proteins were visualized by Coomassie Blue staining. Binding was analysed by quantitative densitometry using a gel densitometer (Molecular Dynamics, Sunnyvale, CA, USA). Binding of native Doc $2 \alpha$ to GST-Munc- 18 proteins was performed as follows. Whole rat brains were homogenized in $320 \mathrm{~mm}$ sucrose, $4 \mathrm{~mm}$ HEPES, $\mathrm{pH} 7.4,1 \mathrm{~mm}$ PMSF using a glass-Teflon homogenizer. The homogenate was centrifuged at $800 \mathrm{~g}$ and $12,000 \mathrm{~g}$ (SS34 rotor, $10 \mathrm{~min}$ ), and $\mathrm{NaCl}$ was added to a final concentration of $150 \mathrm{mM}$. For solubilization of membranes, Triton $\mathrm{X}-100$ was added to yield a final concentration of $1 \%(\mathrm{v} / \mathrm{v})$ and the homogenate was incubated for $30 \mathrm{~min}$ at $4{ }^{\circ} \mathrm{C}$. Insoluble particles were removed by centrifugation at 90,000 $\mathrm{g}$ for $1 \mathrm{~h}$ in a Beckmann $50.2 \mathrm{Ti}$ rotor. Recombinant Munc-18 protein $(180 \mu \mathrm{g})$ bound to GSH beads was incubated for $2 \mathrm{~h}$ at $4{ }^{\circ} \mathrm{C}$ with $50 \mathrm{mg}$ total protein from rat brain homogenates (Triton X-100-extract) on a rotating wheel. Beads were washed five times with TBS-Triton X-100 and finally resuspended in a small volume of TBS-Triton X-100. Samples were analysed by immunoblotting. For the detection of Doc $2 \alpha$, a new polyclonal antiserum against Doc $2 \alpha$ (R93) was raised in rabbits using recombinant full-length Doc $2 \alpha$ as antigen. Aliquots of $\mathrm{His}_{6}$-tagged fusion protein were used for repeated immunization of New Zealand rabbits. Resulting polyclonal antisera were immunity-purified using the antigen expressed as GST-fusion protein coupled to $\mathrm{CNBr}$-activated Sepharose 4B (Amersham).

\section{Cell culture and transfection}

PC12 cells (Greene \& Tischler, 1976; passage number 27-33) were obtained from P. de Camilli and cultured as described previously (Greene et al., 1987). Transfection was performed essentially as described by Lang et al. (1997). Cells used for amperometry were co-transfected with pBOB-EGFP as a marker construct, plated on collagen-coated $35 \mathrm{~mm}$ dishes at densities between 1 and $1.5 \times 10^{6}$ cells/dish and used 3-4 days after transfection. Co-transfection efficiency was analysed from the EGFP signal and immunosignal for the myc-tagged Munc-18 proteins. A molar ratio of $7: 1$ for pBOB-Munc-18 constructs and the EGFP construct was used to guarantee a co-transfection efficiency greater than $85 \%$. A similar ratio was used for transfection with pCMV-Mint1. For amperometric recordings only cells that exhibited strong EGFP signals were used. 


\section{Immunoprecipitation experiments and cell fractionation}

For immunoprecipitation experiments using PC12 cell homogenate, cultured cells were harvested, pelleted and extracted for $45 \mathrm{~min}$ on ice in appropriate volumes of lysis buffer [in mM: NaCl, 150; Tris, 20, pH 7.5; $1 \%$ Triton $\mathrm{X}-100 ; 1 \times$ complete $^{\mathrm{TM}}$ protease inhibitor cocktail incl. EDTA (Roche, Mannheim)]. Insoluble components were removed by centrifugation $(80,000 \mathrm{~g}$ for $45 \mathrm{~min}$; $50.2 \mathrm{Ti}$ rotor Beckmann). Purified antibody $(5-8 \mu \mathrm{g})$ was incubated with $400 \mu \mathrm{g}$ protein from the Triton X-100 extract in a total volume of $200 \mu \mathrm{L}$ lysis buffer for $2 \mathrm{~h}$ at $4{ }^{\circ} \mathrm{C}$ on a shaker. Protein-G-Sepharose bead slurry (40 $\mu \mathrm{L}$, Amersham Pharmacia Biotech) was added and incubation was continued for another $2 \mathrm{~h}$ at $4{ }^{\circ} \mathrm{C}$. Beads were collected by centrifugation and the supernatants ( $\mathrm{S}$ fraction) were decanted. Beads were washed rapidly $(5 \times 2 \mathrm{~min} /$ wash $)$ with $\mathrm{TBS}$ containing $1 \%$ Triton X-100 and were resuspended in a volume (P fraction) equal to that of the supernatant. For fractionation, cells were resuspended in homogenization buffer (20 mM HEPES, pH 7.2, $250 \mathrm{~mm}$ sucrose, $1 \times$ complete $^{\mathrm{TM}}$-cocktail) and cracked by 15 passages through a 23 -gauge needle. Cell debris was removed by centrifugation at $800 \mathrm{~g}$ for $10 \mathrm{~min}$ at $4{ }^{\circ} \mathrm{C}$. The resulting post-nuclear supernatant was centrifuged at $120,000 \mathrm{~g}$ for $1 \mathrm{~h}$ at $4{ }^{\circ} \mathrm{C}$ to obtain cytosol (supernatant) and membrane fractions (high-speed pellet). The high-speed pellet (membrane fraction) was washed once with homogenization buffer, centrifuged in a Beckmann TLA 100.3 at 120,000 $g$ for $20 \mathrm{~min}$ at $4{ }^{\circ} \mathrm{C}$, and solubilized for $25 \mathrm{~min}$ on ice in extraction buffer $(20 \mathrm{mM}$ HEPES, pH 7.2, $100 \mathrm{~mm} \mathrm{NaCl,} 2$ mM EDTA, 1\% Triton X-100, $1 \times$ complete $^{\mathrm{TM}}$-cocktail). Insoluble components were removed by centrifugation at $15,000 \mathrm{~g}$ for $20 \mathrm{~min}$. IP fractions as well as membrane and cytosol fractions were analysed with SDS-PAGE and immunoblotting. For chemiluminescence detection, Supersignal West Dura (Pierce) was used. Biochemical analyses using transfected cells were performed on days 3-4 after transfection.

\section{Quantification of overexpression and determination of endogenous protein levels}

To determine changes in protein levels upon overexpression of Munc18, cultures of PC12 cells grown on plastic dishes were processed for immunolabelling. PC12 cell cultures transfected with EGFP alone served as control. Samples were fixed in 4\% PFAphosphate-buffered saline (PBS) for $30 \mathrm{~min}$ at room temperature, quenched in $50 \mathrm{mM} \mathrm{NH}_{4} \mathrm{Cl}$ in PBS for 10 min and were treated (for $1 \mathrm{~h}$ ) with $15 \%$ goat serum and $0.5 \%$ Triton X-100 in PBS (blocking buffer) for blocking and permeabilization. Primary and secondary antibodies (Texas Red labelled) were applied in a $1: 400$ dilution in blocking buffer. Pictures were taken on the stage of a Zeiss Axiophot2 with a TE/CCD-1317-K/1 CCD camera (Princeton Instruments, Trenton, NJ, USA) and images were analysed using the Metamorph program (Universal Imaging Corporation, West Chester, PA, USA). To quantify the immunosignal from individual cells, isolated cells were selected and an area of interest was defined that comprised the outer cell perimeter omitting the nuclear region. Images were corrected for background fluorescence. Fluorescence values are given as average intensity per pixel.

For quantitative Western blotting, recombinant proteins and samples from PC12 cell cultures were prepared as described above. The monoclonal antibodies HPC-1 and anti-Munc-18 were used to detect syntaxin 1 and Munc-18, respectively. Blots were further incubated with rabbit-anti-mouse antibody (bridge antibody; dilution: $1: 1000$; Pierce) and with ${ }^{125}$ I-Protein A (Blotting Grade, Amersham Pharmacia Biotech) using $2 \mu \mathrm{Ci}$ per membrane. Signals were quantified by a
Fujifilm BAS-2500 system and the image analysis program AIDA 2.11 (Raytest, Straubenhardt, Germany). Intensity values were corrected for background radioactivity.

\section{Analysis of granule number}

For microscopic analysis of LDCVs, PC12 cells were cultured, transfected and fixed as described in Lang et al. (2001). Cells transfected with NPY-EGFP alone or in combination with Mint1, Munc-18-WT/-D34N/-R39C were used $48 \mathrm{~h}$ after transfection. Overexpressed protein was immunostained using the anti-myc antibody in combination with a Cy3-labelled goat-anti-mouse secondary antibody (Dianova), as previously described (Lang et al., 1997). Cells were then incubated with Tetraspek ${ }^{\mathrm{TM}}$ beads diluted 1:50 in PBS. For imaging, cells were selected that displayed average expression levels of NPY-EGFP, were in close proximity to several Tetraspek ${ }^{\mathrm{TM}}$ beads, and were immunopositive for the overexpressed protein. Using a piezoelectric focusing device, the objective was moved in 100-nm steps (corresponding to $88-\mathrm{nm}$ steps of the focal plane; Majlof \& Forsgren, 1993) through the cells, starting at 200-400 nm below the coverslip. A stack of 30 pictures (corresponding to a total sample thickness of $2.6 \mu \mathrm{m}$ ) was averaged and low-pass filtered (spatial constant $812.5 \mathrm{~nm}$ ). Granules were counted on the averaged image in an area of $40 \mu \mathrm{m}^{2}$ corresponding to a volume of $105 \mu \mathrm{m}^{3}$. The identity of fluorescent spots as individual granules (within the average image) was routinely verified by visual inspection of consecutive images within the stack. The fluorescence signal of the individual granule shows a bell-shaped dispersion in the axial direction (Lang et al., 2000) with a width of approximately $1280 \pm 250 \mathrm{~nm}$ at $50 \%$ of the maximum fluorescence intensity comprising about half of the entire sample depth. Cells were analysed on the stage of a Zeiss Axiovert 100 TV fluorescence microscope with a $100 \times 1.4$ NA plan achromate objective. A back-illuminated frame transfer CCD-camera $(2 \times 512 \times 512$-EEV chip, $13 \times 13 \mu \mathrm{m}$ pixel size, Princeton Instruments) with a magnifying lens (1.6 x Optovar) to avoid spatial undersampling by the large pixels was used for imaging. EGFPfluorescence was detected using excitation filter BP 480/40, BS 505 and emission filter BP 527/30 (AHF Analysentechnik AG, Tübingen, Germany). Cy3-fluorescence was detected using excitation filter BP 565/30, BS 595 and emission filter BP 645/75 (AHF Analysentechnik AG, Tübingen, Germany). Fluorescent Tetraspek ${ }^{\mathrm{TM}}$ beads (diameter $220 \mathrm{~nm}$; Molecular Probes) could be distinguished from secretory granules using Zeiss filter set 02 (excitation filter G 365, BS 395 and emission LP 420). Images were analysed with Metamorph.

\section{Line scan analysis}

PC12 cells were cultured (as described above) and transfected with EGFP-Munc-18-WT/-D28N/-R39C, Syntaxin1A-EGFP or with EGFP alone. Forty-eight hours after transfection, randomly selected cells were imaged using a Zeiss Axiovert 100 TV fluorescence microscope with a $100 \times 1.4$ NA plan achromate objective and a back-illuminated frame transfer CCD-camera $(2 \times 512 \times 512$-EEV chip, $13 \times 13 \mu \mathrm{m}$ pixel size; Princeton Instruments) with a magnifying lens $(1.6 \times$ Optovar $)$ to avoid spatial undersampling by large pixels. GFP fluorescence was elicited using a filter set F41-054 (excitation filter BP 480/40, BS Q 505 LP, emission filter BP 527/30; AHF Analysentechnik AG, Tübingen, Germany) and images were analysed with Metamoph (Universal Imaging, West Chester, PA, USA). One line scan per cell was performed over a distance of $6.9 \mu \mathrm{m}$ (width $1.6 \mu \mathrm{m}$ ) with $2 / 5$ of the scanned distance extending into the 
cell. The line scan was orientated perpendicular to the plasma membrane at regions without cell-cell contact and far enough from the nucleus. For averaging, line scans were corrected for background fluorescence, normalized to the maximum value and were aligned with respect to the 'nose'-like upward deflection of the fluorescence signal indicating the position of the plasma membrane. In test experiments with the membrane marker TMA-DPH we found that the maximum slope of the EGFP signal (cytosolic only) marks the position of the plasma membrane. Fluorescence values are given as mean $\pm \mathrm{SEM}$.

\section{Electrophysiology}

Carbon fibre amperometry was used essentially as described (Bruns et al., 2000). Amperometric signals were recorded with an EPC-7 amplifier (Heka Electronics holding potential set to $+800 \mathrm{mV}$ ). The tip of the carbon fibre was brought into direct contact with the plasma membrane to minimize temporal distortion of the release signal and diffusional loss of the released transmitter amount. Experiments were performed in Ringer's solution containing (in mM: $\mathrm{NaCl}, 130 ; \mathrm{KCl}, 4$; HEPES, 10, $\mathrm{pH} 7.4 ; \mathrm{MgCl}_{2}, 1 ; \mathrm{CaCl}_{2}, 5$; glucose, 44). Signals were filtered with $3 \mathrm{kHz}$ and $10 \mathrm{kHz}$ (overall band with $2.3 \mathrm{kHz}$ ), digitized at $25 \mathrm{kHz}$ and stored on a personal computer. Using a multichannel perfusion pipette (Bruns, 1998), a depolarizing stimulus was applied by rapid superfusion with (in $\mathrm{mM}$ ): $\mathrm{NaCl}, 80 ; \mathrm{KCl}, 50$; HEPES, 10 , pH 7.4; $\mathrm{MgCl}_{2}, 1 ; \mathrm{CaCl}_{2}, 5$; glucose, 24; tetraethylammonium chloride, 20. Stimulation periods were bracketed by superfusion with Ringer's solution. For stimulation with the calcium ionophore, Ionomycin Ringer's solution containing $1 \mathrm{mM} \mathrm{CaCl}_{2}$ was supplemented with $5 \mu \mathrm{M}$ ionomycin. For data analysis, the AutesW software (NPI Electronics, Tamm, Germany) was used as described in Bruns et al. (2000). Signals were again digitally filtered at $3 \mathrm{kHz}$ (effective band width $2.1 \mathrm{kHz}$ ). Additionally, a routine for analysis of foot events preceding the main amperometric spike was included. The start of the foot signal was defined as the point where the current amplitude exceeded twice the standard deviation of the average baseline noise and its end was defined as the inflection point where the slowly increasing foot signal turns into the more rapid increase in current amplitude initiating the main spike phase.

\section{Results \\ The subcellular distribution of Munc-18 depends on direct binding to syntaxin 1}

The mechanisms by which Munc-18 binds to membranes are likely to be important for its function in neurotransmission. Here, we first studied whether a selective perturbation of syntaxin binding is sufficient to produce a significant loss of Munc-18's association with membranes. Two point mutations (R39C and D34N) were used that localize to the syntaxin-binding region as judged from the $3 \mathrm{D}$ structure of the Munc-18/syntaxin1a complex (Misura et al., 2000). Recombinant Munc-18-WT binds efficiently to GST-syntaxin immobilized on Sepharose beads but not to control beads (Fig. 1A and B). The R39C mutant exhibits only reduced binding to syntaxin, whereas the D34N mutation causes a more severe phenotype preventing any significant complex formation. To study the interactions of the Munc18 proteins with endogenous syntaxin, myc-tagged versions of Munc18 variants were overexpressed in $\mathrm{PC} 12$ cells and their interaction with endogenous syntaxin1 was analysed by co-immunoprecipitation (Fig. 1C). Again, syntaxin1 co-precipitates with wild-type Munc-18, indicating that the overexpressed protein participates in protein complex formation in vivo. For the R39C mutant, significantly less syntaxin1 co-precipitated (only being detectable on overexposed Western blots). For the D34N mutant, no syntaxin1 was observed in the immunoprecipitate, in agreement with the results obtained with purified recombinant proteins (Fig. 1A).

To assess the subcellular distribution of the Munc-18 variants, postnuclear supernatants from PC12 cell cultures were fractionated into membranes and cytosol and analysed by immunoblotting. A major portion of the endogenous Munc-18 in control cells is found in membrane fractions (Fig. 1D, right panel). Importantly, the overexpressed Munc-18-WT protein shows a similar distribution, demonstrating that, even upon overexpression, the majority of the protein associates with intracellular membranes (Fig. 1D). The mutant R39C still concentrates on membranes, but to a lesser extent than wild-type protein, whereas the majority of the non-syntaxin binding mutant D34N accumulates in the cytosol. As expected the soluble protein GDI is found in the cytosolic fraction and a similar distribution is observed for the Munc-18 binding protein Mint1, agreeing with previous observations by Borg et al. (1998). To study whether Munc18 wild-type and mutant proteins exhibit a differential binding to membranes also in vivo we performed fluorescence imaging of PC12 cells overexpressing EGFP-tagged variants of the proteins. For Munc18 wild-type protein, clear labelling of the plasma membrane is apparent that resembles the EGFP-signal observed for syntaxin (compare Fig. 2A and C). In contrast, the mutant proteins (Fig. 2D and E) exhibit less labelling on the plasma membrane, consistent with our biochemical results. Taken together, these findings confirm the view that membrane association of Munc-18 depends on direct interaction with syntaxin.

To estimate the change in protein levels reached upon overexpression we quantitatively analysed the immunofluorescence signals for Munc18 in transfected and control cells. Fluorescence levels of cells overexpressing WT protein increase on average 10-fold compared with endogenous levels in control cells (Fig. 3A, control: $308 \pm 7820$ a.u.; wild-type overexp. $3240 \pm 1800$ a.u). A similar increase in intracellular protein levels is observed upon overexpression of the mutant proteins, Munc-18-D34N and -R39C. To determine the relative amounts of Munc-18 and syntaxin, we quantified their immunosignals with Western blot analysis and ${ }^{125}$ I-labelled ProteinA. Immunosignals were calibrated with standard curves comprising various amounts of both recombinant proteins (Fig. 3B). As shown in Fig. 3C, immunosignals for Munc-18 and syntaxin 1 increase proportionally with increasing amounts of protein loaded to the gel lanes. Syntaxin1 was found to be in an approximately 20-fold excess over Munc-18 (syntaxin: $104 \mathrm{fmol} / \mu \mathrm{g}$ total protein; Munc-18: $5 \mathrm{fmol} / \mu \mathrm{g}$ total protein) comprising about $0.3 \%$ of the total protein content. Notably, syntaxin 1 remains in excess over Munc-18, even after its 10-fold overexpression (ratio $2: 1$ ). This result is compatible with a syntaxin1-mediated membrane accumulation of overexpressed Munc-18 (Fig. 1D).

\section{Munc-18 mutants with impaired syntaxin binding display different effects on exocytosis}

We next investigated how overexpression of Munc-18 variants affects exocytosis in PC12 cells. To study their functional impact on calciumdependent exocytosis, dopamine release from LDCVs was monitored with carbon fibre amperometry. Upon stimulation with high $\mathrm{K}^{+}$-containing Ringer's solution, control cells (overexpressing EGFP) respond with a transient increase in the frequency of exocytotic signals (Fig. 4A-C). Overexpression of wild-type protein leaves the exocytotic response unchanged. Still, perturbation of endogenous Munc18 /syntaxin interactions by overexpression of the R39C mutant 
A

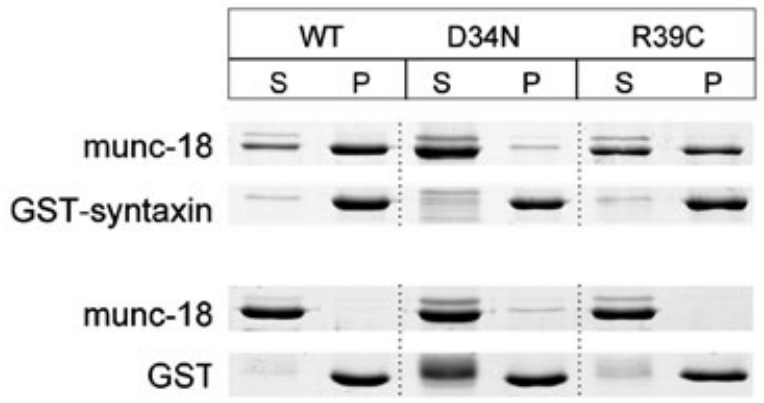

C

\begin{tabular}{|ll|ll|ll|ll|}
\hline \multicolumn{2}{|c|}{ WT } & \multicolumn{2}{c}{ D34N } & \multicolumn{2}{c|}{ R39C } & \multicolumn{2}{c|}{ control } \\
\hline S & P & S & P & S & P & S & P \\
\hline
\end{tabular}

myc-munc-18

syntaxin 1

syntaxin1 overexposed
B

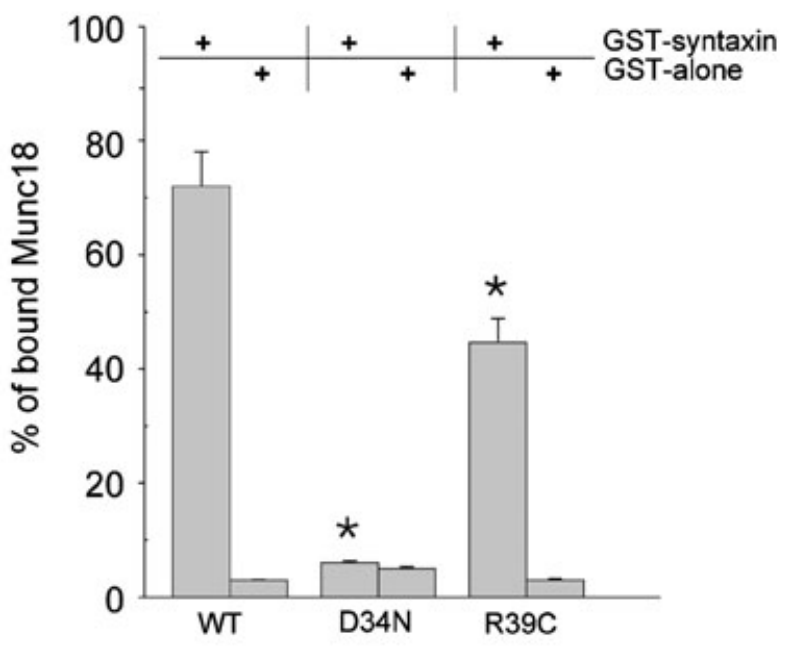

D
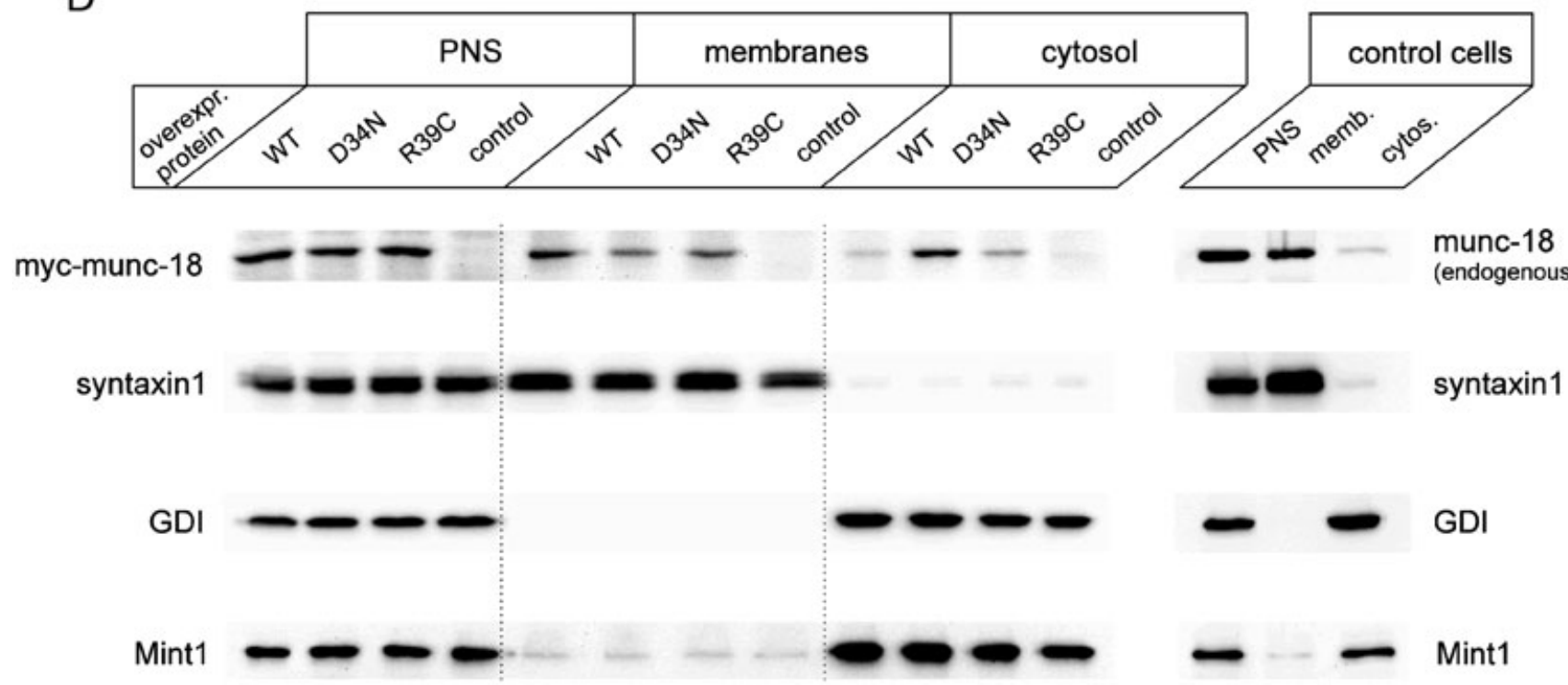

FIG. 1. Munc-18 binds to membranes in a syntaxin-dependent manner. (A) Binding of recombinant Munc-18-WT/-D34N/-R39C proteins to GST-syntaxin. Munc-18 $(1.8 \mu \mathrm{M})$ was incubated with $3.2 \mu \mathrm{M}$ GST-syntaxin or with equimolar amounts of GST, immobilized on GSH-beads and analysed with SDS-PAGE. Protein binding was analysed on Coomassie-stained gels. S, supernatant (non-bound); P, pellet (bound). Munc-18-WT binds efficiently to GST-syntaxin (cytoplasmic domain, aa 1-272, upper two panels) but not to GST alone (lower two panels). No binding occurs between syntaxin and the D34N mutant whereas approximately equimolar amounts of the R39C protein are present in the pellet and the supernatant fraction. The band with an approximate molecular weight similar to GST in the D34N supernatant fraction is a bacterial contaminant. (B) Quantification of Munc-18 binding to GST-syntaxin1A or GST-alone, as shown in (A). The percentage of bound Munc-18 was analysed by quantitative densitometry of the proteins stained with Coomassie blue. Data were collected from six independent experiments. *The one-way analysis of variance indicates that differences in binding of Munc-18 variants to syntaxin are very significant $(P<0.01)$, and the TukeyKramer post-test shows significant differences for D34N $(P<0.05)$ and R39C $(P<0.05)$ binding compared with WT protein. (C) Co-immunoprecipitation experiments of syntaxin with myc-tagged Munc-18 proteins after overexpression in PC12 cells. The immunoprecipitates (P) and the remaining supernatants (S) were analysed by Western blotting using horseradish peroxidase-coupled secondary antibodies and an ECL system for detection. Control, non-transfected PC12 cells. For detection of Munc-18 and syntaxin, anti-myc and HPC-1 antibody were used, respectively. To increase sensitivity, blots were also overexposed (bottom panel), revealing a small amount of syntaxin bound to the R39C mutant, whereas no binding above background was detectable for the D34N mutant. The same result was obtained in five independent experiments. (D) Membrane association of Munc-18 variants, monitored by subcellular fractionation. A post-nuclear supernatant (PNS) of PC12 cells overexpressing Munc-18-WT/-D34N/-R39C or control cells (non-transfected) was subfractioned into membranes and cytosol. Fractions were analysed by immunoblotting for the indicated proteins. Right panels: fractions obtained from untransfected cells. Expression levels of Munc-18-WT/-D34N/R39C protein are similar. Both Munc-18 mutants bind less efficiently to membranes compared with WT protein and show increased cytosolic protein levels. The same result was obtained in four independent experiments. Note that the membrane protein syntaxin1 and the soluble protein guanine dissociation inhibitor (GDI) are restricted to the membrane and supernatant fractions, respectively, indicating that cross-contamination is negligible. 

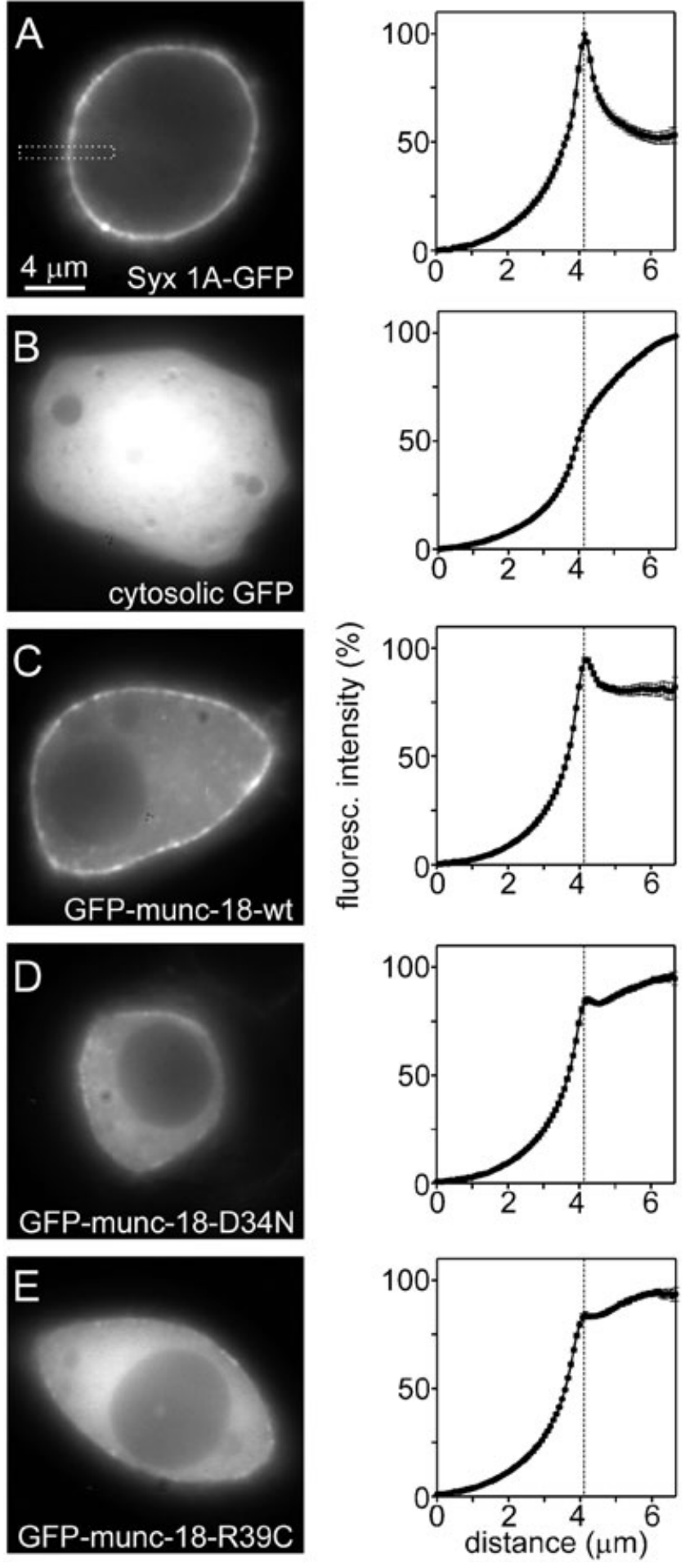

FIG. 2. Live imaging of cells overexpressing EGFP-tagged variants of syntaxin1A and Munc-18 or EGFP alone. (A and B) Syntaxin1A-EGFP concentrates at the plasma membrane, whereas EGFP (alone) accumulates in the cytosol. (C) EGFP-Munc-18 wild-type protein produces a strong staining at the plasma membrane and in addition some fluorescence in the cytosol. (D and E) In contrast the fluorescence signals for EGFP-tagged mutant proteins exhibit less staining at the plasma membrane and a more pronounced signal in the cytosol. Right panels: spatial changes of the EGFP-fluorescence signal obtained from averaged line scans across the plasma membrane (e.g. dotted line in A) illustrating the differential subcellular distribution of the proteins (syntaxin1A, 21 cells; EGFP, 19 cells; Munc-18-WT, 33 cells; Munc-18D34N, 37 cells, Munc-18-R39C, 36 cells). significantly attenuates the exocytotic response by nearly $50 \%$ (Fig. 4C), supporting the view that binding of Munc-18 to syntaxin represents an intermediate step leading to exocytosis (Misura et al., 2000). The same results are obtained when cells are stimulated with the calcium ionophore ionomycin (Fig. 4D and E). This renders the possibility unlikely that the mutants' effect is due to changes in a syntaxin-dependent regulation of calcium channel activity (Atlas, 2001), but rather suggests that impaired syntaxin binding interferes directly with the exocytotic mechanism. Notably, overexpression of the non-syntaxin-binding mutant D34N leads to a strong increase in the frequency of the exocytotic signals (Fig. 4B and C) that is also seen upon stimulation with ionomycin (Fig. 4D and E). Thus, not only reduced syntaxin binding of the Munc-18 mutants, but also changes in the interactions with other proteins should be responsible for the different phenotypes of the mutant proteins.

\section{Does Munc-18 influence the individual release event?}

Recent studies have suggested that overexpression of the Munc18-R39C mutant alters the kinetics of catecholamine release from chromaffin granules (Fisher et al., 2001), an observation that has been attributed to a perturbation of syntaxin binding. To address this issue we determined the properties of individual amperometric signals with respect to quantal size, amplitude and kinetic parameters. The results are summarized in Table 1. Our analysis does not reveal any significant differences for cells overexpressing wild-type or mutant protein compared with controls. To minimize the possibility that putative alterations of the amperometric signal time course remain occluded by diffusional distortion, we, furthermore, restricted our analysis to events with amplitudes larger than $8 \mathrm{pA}$ or to those with rise times faster than $500 \mu \mathrm{s}$. These criteria comprised about $30 \%$ and $40 \%$ of all events, respectively, and should preferentially select fusion events that occur closest to the carbon fibre. Again, under both conditions, no significant differences are seen between the experimental groups (data not shown). The foot signal preceding the main amperometric spike reflects transmitter leakage through a narrow fusion pore formed at the onset of exocytosis (Chow et al., 1992; Alvarez de Toledo et al., 1993; Albillos et al., 1997). Such signals should therefore be especially sensitive to factors influencing fusion pore dynamics. As shown in Table 1, neither the proportion of events with a foot (about 30\%) nor the properties of the individual foot signals are changed in cells overexpressing wild-type or mutant protein when compared with controls. In summary, the results indicate that perturbation of Munc18 function affects the number of organelles competent for exocytosis but not the kinetics of catecholamine secretion from individual granules.

\section{Evidence for a Munc-18/Mint interaction in exocytosis}

Having shown that control of exocytosis by Munc-18 does not appear to be exclusively mediated by interacting with syntaxin, we extended our experiments to other known binding partners of Munc-18, Mint1 and Doc2 $\alpha$ (Okamoto \& Südhof, 1997; Verhage et al., 1997). As shown in Fig. 5A, wild-type and mutant variants of Munc-18 bind equally well to GST-Mint1 immobilized on beads giving no indication for differential binding of the mutant proteins. Munc-18 has been described as part of a trimeric complex together with Mint1 and syntaxin1 (Okamoto \& Südhof, 1997), raising the question of whether addition of syntaxin may reveal a differential pattern of complex formation. In agreement with previous observations by 
A

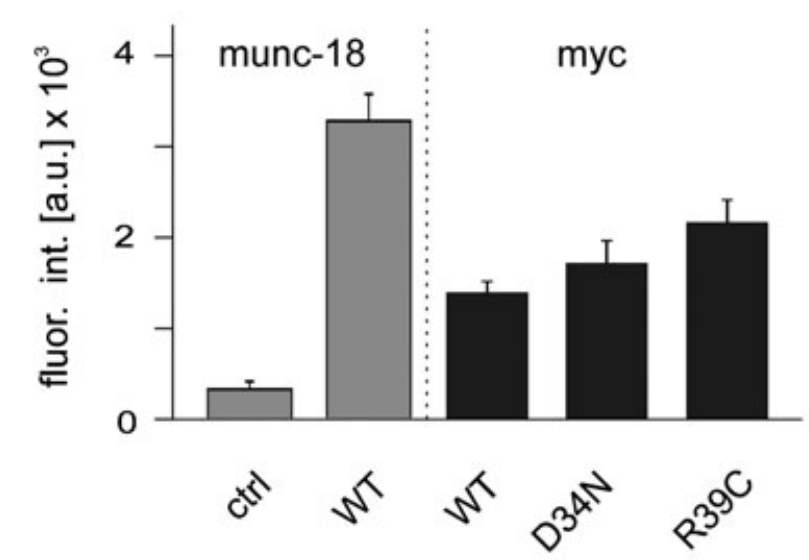

B
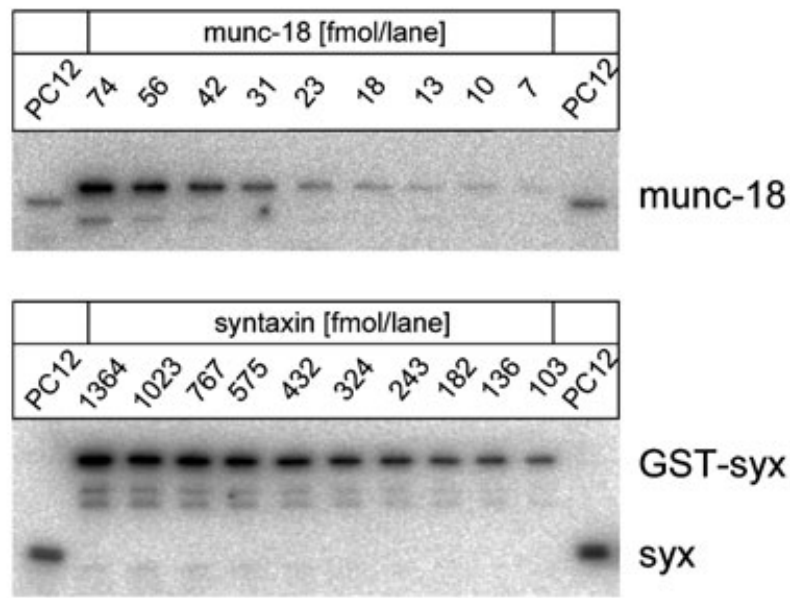

C

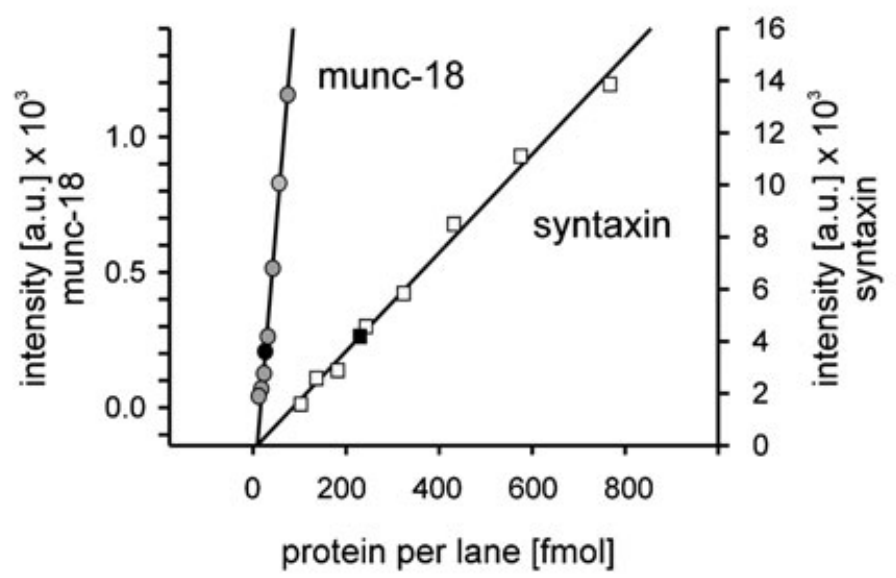

FIG. 3. Syntaxin exists in a large excess over Munc-18 in PC12 cells. (A) Quantitative analysis of fluorescence intensities from single immunolabelled cells, stained either with an anti-Munc-18 antibody (grey bars, left) or with an anti-myc antibody (black bars, right) and analysed by epifluorescence microscopy using a video camera. Fluorescence intensities are given as average intensity (arbitrary units, a.u.) per area \pm SD (see Materials and methods for details). Munc-18overexpressing cells were reliably identified by co-transfection with an EGFP-encoding plasmid (co-transfection efficiency about $85 \%$ ). The anti-Munc-18 fluorescence signal strongly increases from $308 \pm 78$ a.u. in controls $(n=41$ cells) to $3243 \pm 1800$ a.u. upon transient overexpression of Munc-18-WT protein ( $n=43$, grey bars). Similar expression levels (black bars) were reached for all three Munc-18 variants (stained with anti-myc antibody; WT, $n=50$ cells; D34N, $n=35$ cells; R39C, $n=36$ cells). Immunosignals were corrected for background fluorescence of non-transfected cells stained with the anti-myc antibody. (B) Quantification of endogenous syntaxin and Munc-18 by immunoblotting of PC12 cell homogenates ( 2.5 and $5 \mu \mathrm{g}$ of protein, respectively), using defined amounts of recombinant proteins for calibration. Immunoreactive bands were developed with ${ }^{125}$ I-labelled Protein A followed by autoradiography. (C) Quantitative analysis by densitometry of the immunoblots shown in (B). A linear relationship between signal intensity and the amounts of recombinant protein loaded per gel lane was obtained (linear regression, solid lines). Syntaxin 1 ( $260 \mathrm{fmol} / 2.5 \mu \mathrm{g}$ homogenate, filled square) was found to be in a $\sim 20$-fold excess over Munc-18 ( $25 \mathrm{fmol} / 5 \mu \mathrm{g}$ homogenate, filled circle). The densitometric signals were corrected for background and included only the major band of the recombinant protein. Intensity values for the degradation products of Munc-18 and syntaxin 1 (see B) comprise about $17 \%$ and $15 \%$ of major band's intensity of Munc-18 and syntaxin, respectively.

Südhof and co-workers, immobilized GST-Mint1 precipitates Munc18-WT together with a small but detectable amount of syntaxin1a (Fig. 5B). A similar result is obtained for the R39C mutant. However, the majority of Munc-18-WT and the mutant R39C remains together with syntaxin in the supernatant suggesting that syntaxin 1 and Mint1 preferentially compete for Munc-18 binding rather than forming a trimeric complex (compare Fig. 5A and B). In close correlation binding of the D34N mutant to Mint1 is unchanged in the presence of syntaxin, as expected for a mutant protein lacking any detectable syntaxin binding (Fig. 5B, for quantification of Munc-18 binding to Mint1, see Fig. 5C). Thus, the combination of all three binding partners, as under in vivo conditions, reveals a differential action of the mutant proteins that may serve as a mechanism for their opposite effects on exocytosis. It is conceivable that the stimulatory phenotype observed upon overexpression of the D34N mutant may result from more frequent interactions with the Mintl protein. To find support for this hypothesis, we overexpressed Mint1 in PC12 cells and studied the functional consequences by carbon fibre amperometry. In fact, increases in Mint1 levels have a profound effect on the exocytosis pathway, leading to a $50 \%$ reduction in the number of stimulated events (Fig. 5E-G). No significant alterations of the individual event properties were observed (Table 1). Taking the biochemical and physiological data together, a picture emerges in which the stimulatory effect of the Munc-18-D34N mutant is best explained by sequestration of inhibitory Mint1. The R39C mutant may also exert a similar stimulatory effect on exocytosis via Mint1 binding but, in addition, perturbs the endogenous Munc-18-syntaxin1 interaction, leading to a strong impairment of secretion. 
A
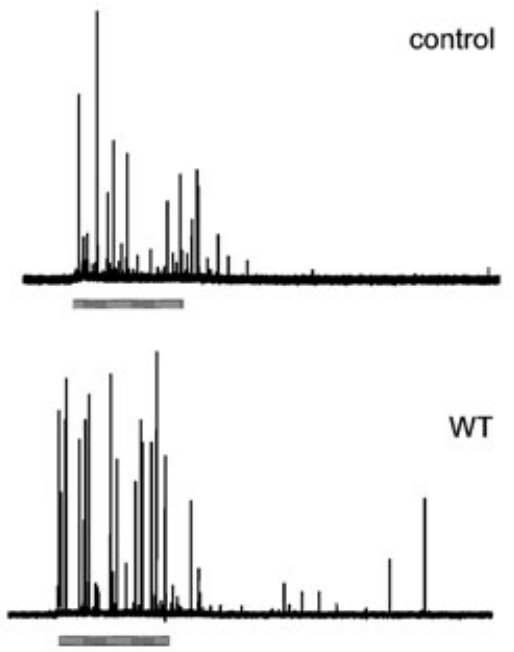

B

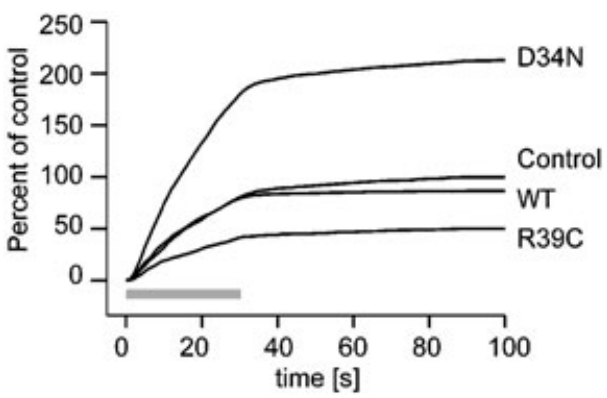

D

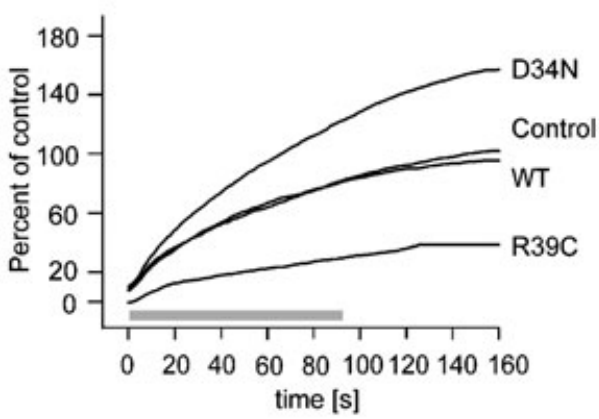

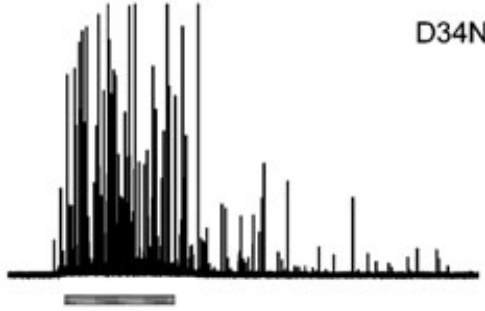

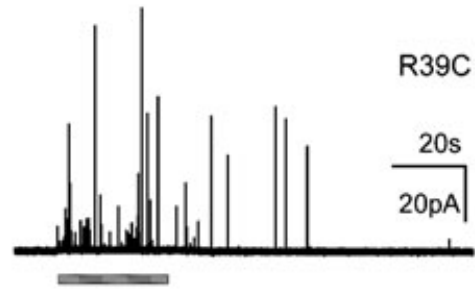

C

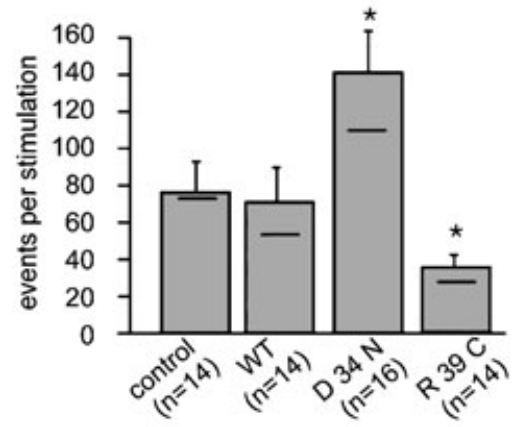

E

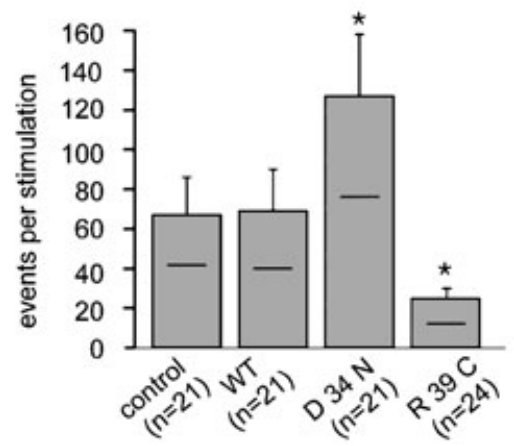

FIG. 4. Differential effects on LDCV exocytosis upon overexpression of Munc-variants in PC12 cells. (A) Exemplary amperometric current traces recorded upon high $\mathrm{K}^{+}$stimulation from control cells and cells overexpressing Munc-18-WT/-D34N/-R39C. Overexpression of the D34N mutant protein leads to a strong increase in the exocytotic response, whereas overexpression of the R39C mutant causes a strong decrease. No alterations are observed upon overexpression of Munc18 wild-type protein when compared with control cells expressing only EGFP (bar indicates stimulation with high $\mathrm{K}^{+}$solution). (B) Cumulative plot of the number of amperometric spikes evoked by depolarization with high $\mathrm{K}^{+}$(bar) in the different test groups. Data are normalized to the maximum number of events recorded from control cells (control, 1008 events, 14 cells; Munc-18-WT, 910 events, 14 cells; Munc-18-D34N, 2208 events, 16 cells; Munc-18-R39C, 504 events, 14 cells). (C) Mean number of events per stimulation for control cells and Munc-18-WT/-D34N/-R39C overexpressing cells upon high $\mathrm{K}^{+}$stimulation (mean $\pm \mathrm{SEM}$ ). Horizontal lines within the bars indicate the median values of the frequency distributions. ${ }^{*}$ signifies $P<0.001$ with one-way analysis of variance for differences between cell populations and a Tukey-Kramer post-test comparing D34N $(P<0.05)$ or R39C $(P<0.05)$ effect with control. (D) Cumulative events analysis from control cells and Munc-18-WT/-D34N/-R39C overexpressing cells stimulated by application of $5 \mu \mathrm{M}$ of the calcium ionophore ionomycin (bar). Data are normalized to the maximum number of events recorded in control cells (control, 1257 events, 21 cells; Munc-18-WT, 1380 events, 21 cells; Munc-18-D34N 2413 events, 21 cells; Munc-18-R39C, 576 events, 24 cells). Four (out of 28 R39C-overexpressing) cells had release frequencies that exceeded the median value by more than 10 times. These cells were excluded from the analysis as a similar variability was not observed for the other test groups. (E) Mean number of events per stimulation for the indicated test groups (mean \pm SEM). The median values of the frequency distributions are indicated as horizontal lines within the bars. $* P<0.001$, with one-way analysis of variance for differences between cell populations and a Tukey-Kramer post-test comparing D34N $(P<0.05)$ or R39C $(P<0.05)$ effect with control. 
TABLE 1. Characterisics of release events in PC12 cells overexpressing munc-18-WT, -18-D34N, -18-R39C and -18-Mint1

\begin{tabular}{|c|c|c|c|c|c|}
\hline & Control & WT & $\mathrm{D} 34 \mathrm{~N}$ & $\mathrm{R} 39 \mathrm{C}$ & Mint1 \\
\hline Number of cells & 14 & 14 & 16 & 14 & 19 \\
\hline Events per stimulus & $72 \pm 12$ & $65 \pm 13$ & $138 \pm 21^{*}$ & $36 \pm 5^{*}$ & $30 \pm 5^{*}$ \\
\hline Total events analysed per group & 1008 & 910 & 2208 & 504 & 570 \\
\hline \multicolumn{6}{|c|}{ Characteristics of main amperometric spike } \\
\hline Charge (fC) & $26.6 \pm 8.6$ & $26.3 \pm 13.3$ & $28.2 \pm 9.4$ & $23.2 \pm 8.6$ & $22.5 \pm 10.7$ \\
\hline Peak amplitude (pA) & $4.6 \pm 1.4$ & $4.2 \pm 1.6$ & $5.2 \pm 2.1$ & $4.4 \pm 3.0$ & $3.6 \pm 1.4$ \\
\hline Rise-time (50 to $90 \%)(\mu \mathrm{s})$ & $607 \pm 296$ & $870 \pm 650$ & $730 \pm 456$ & $912 \pm 627$ & $897 \pm 579$ \\
\hline Half-width $(\mu s)$ & $3078 \pm 1368$ & $3814 \pm 2373$ & $3698 \pm 1843$ & $3824 \pm 2239$ & $3821 \pm 1984$ \\
\hline \multicolumn{6}{|c|}{ Characteristics of foot preceding spike } \\
\hline Foot amplitude $(\mathrm{pA})$ & $3.4 \pm 1.4$ & $4.8 \pm 1.5$ & $4.8 \pm 1.7$ & $4.0 \pm 2.0$ & $4.7 \pm 3.0$ \\
\hline Foot charge (fC) & $5.0 \pm 2.6$ & $8.1 \pm 4.7$ & $7.8 \pm 3.1$ & $4.5 \pm 2.5$ & $9.9 \pm 7.7$ \\
\hline Foot duration $(\mu \mathrm{s})$ & $2421 \pm 830$ & $3207 \pm 1984$ & $2783 \pm 965$ & $2052 \pm 700$ & $3325 \pm 1340$ \\
\hline Events with foot (\%) & $24.7 \pm 14.3$ & $18.9 \pm 12.0$ & $24.6 \pm 14.7$ & $21.7 \pm 17.7$ & $11.4 \pm 10.0$ \\
\hline
\end{tabular}

Measurements are given as mean $( \pm \mathrm{SD})$ of median values determined for the individual cells except for events per stimulus (mean \pm SEM) and events with foot (mean $\% \pm \mathrm{SD}$ ). The half-width gives the duration of the current transient at half-height of its peak amplitude. $* P<0.0001$ with one-way analysis of variance for differences between cell populations [and with Tukey-Kramer post-test comparing D34N $(P<0.05), \mathrm{R} 39 \mathrm{C}(P<0.05)$ and Mint1 $(P<0.01)$ effects with control].

We also studied whether the Munc-18 variants exhibit differential binding to Doc2 $\alpha$ (Verhage et al., 1997). Unexpectedly, no binding between GST-Munc-18 protein and native Doc $2 \alpha$ from rat brain homogenate could be detected (Fig. 5D), contrasting previous reports by Verhage et al. Using a variety of experimental approaches we neither observed binding between recombinant proteins nor between native proteins using immunoprecipitations from rat brain homogenate (not shown). Furthermore, we found that Doc $2 \alpha$ is virtually undetectable on immunoblots of PC12 cells (Fig. 5D). While other hitherto unknown interactions of Munc-18 likely exist, it seems safe to conclude that Munc-18 has at least a dual role, and may serve as a link between syntaxin-related and Mint1-related functions (Fig. 7; for details see Discussion).

\section{LDCV numbers are not changed by perturbation of Munc-18 function}

To assess the question if the observed changes in release frequency may simply reflect changes in the biogenesis of the granules, we determined the number of LDCVs in cells overexpressing the proteins. For this, secretory granules of cultured PC12 cells were visualized by overexpressing EGFP-tagged NPY-EGFP that is sorted into newly formed LDCVs (Lang et al., 1997; Holroyd et al., 2002). Cells expressing NPY-EGFP alone (control) or in combination either with Mint1 or with one of the Munc-18 proteins were examined. A stack of 30 individual epifluorescence images (vertical distances between images $\sim 88 \mathrm{~nm}$ ) was acquired focusing from the footprint of the cells at the coverslip surface into deeper regions of the cells (maximum depth $2.6 \mu \mathrm{m}$; Fig. 6A and B, see Materials and methods for details). Fluorescence beads served as reference points to define the axial position of the coverslip and an average image (calculated from the individual images) was used for counting of NPY-EGFP-positive granules (Fig. 6C). We found that the fluorescence signal of the individual granule shows a bell-shaped dispersion in axial direction (Lang et al., 2000), with a width of approximately $1280 \pm 250 \mathrm{~nm}$ at $50 \%$ of the maximum fluorescence intensity comprising about half of the entire sample depth. Thus, the resolution of this assay is too low to analyse changes in the spatial distribution of the granules. However, we found that granules from all focal planes of the stack were visible on the average image, as judged from the analysis of consecutive image planes (compare Fig. 6A-C). As shown in Fig. 6D, no changes in the number of NPY-EGFP-positive granules could be detected, indicating that overexpression of the Munc-18 variants or of Mint1 leaves the de novo synthesis of LDCVs unchanged.

\section{Discussion}

In this study we set out to gain insight into the molecular role of Munc-18 in the exocytotic response of PC12 cells. For this, we took advantage of two point mutations within Munc-18 that perturb the Munc-18/syntaxin interaction and that had been previously shown to alter synaptic transmission in Drosophila (Harrison et al., 1994; Wu et al., 1998). Our combined electrophysiological and biochemical analyses support the view that Munc-18 influences exocytosis via distinct and predominantly exclusive interactions with syntaxin and Mint1. Furthermore, we provide evidence that Munc-18 acts upstream of membrane fusion rather than at the level of membrane merger. Taken together, Munc-18 seems to serve as an important molecular link that regulates both membrane-bound as well as cytosolic events in the cascade of protein-protein interactions leading to exocytosis.

\section{Membrane association of Munc-18}

Previous experiments by Garcia et al. (1995) suggested that Munc-18 exhibits properties of membrane association that are characteristic for hydrophobic interactions. Furthermore, the authors found little evidence for a stable complex between syntaxin and Munc-18 using immunoprecipitations from rat brain homogenate. In contrast, a more recent study by Perez-Branguli et al. (2002) shows that membrane association of Munc-18 in 29.3T-cells depends on the heterologous expression of syntaxin. To elucidate the molecular mechanism of membrane association in neuroendocrine cells we studied the effects of point mutations within the Munc-18 protein that should, based on the 3D structure of the Munc-18/syntaxin complex (Misura et al., 2000), either affect amino acids directly contacting the syntaxin H3-domain (R39C) or change the architecture of the syntaxin-binding region $(\mathrm{D} 34 \mathrm{~N})$. As predicted from the crystal structure, we found that the mutant proteins differ significantly in binding to syntaxin. While the D34N mutation abolishes any detectable binding to syntaxin, the R39C defect allows for less but still significant binding to syntaxin. Using cell fractionation we found that the membrane association of the mutant proteins parallels their ability to interact with syntaxin. In the same line, overexpressed Munc-18-WT protein concentrates in membrane fractions of PC12 cells and co-precipitates syntaxin1. 
A

\begin{tabular}{|l|l|l|l|}
\hline WT & D34N & R39C \\
\hline S P & S P & S P P \\
\hline
\end{tabular}

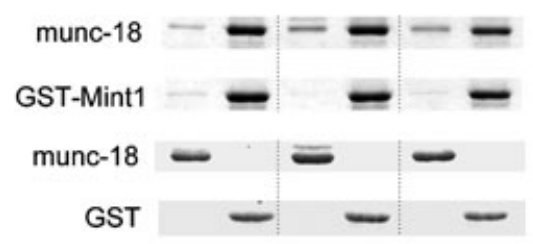

C

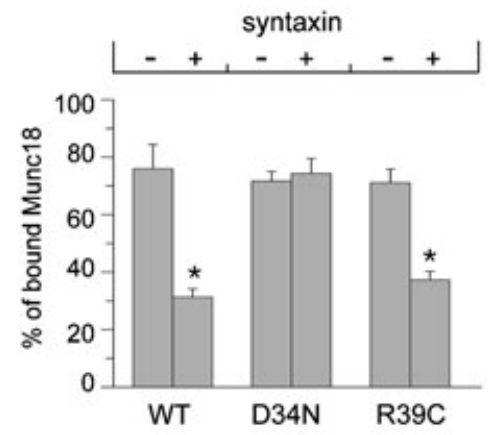

E

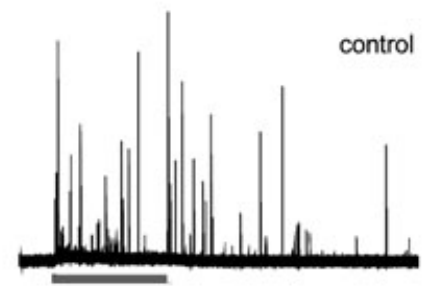

F

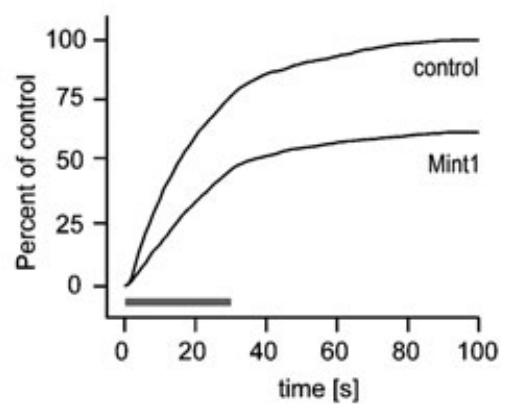

B

\begin{tabular}{|c|c|c|}
\hline WT & D34N & R39C \\
\hline$S \quad P$ & $S \quad P$ & \\
\hline
\end{tabular}

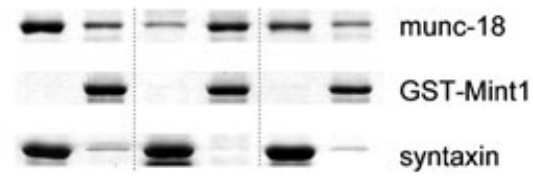

D

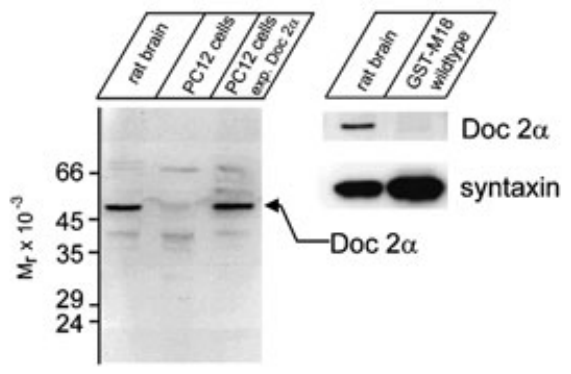

Mint1

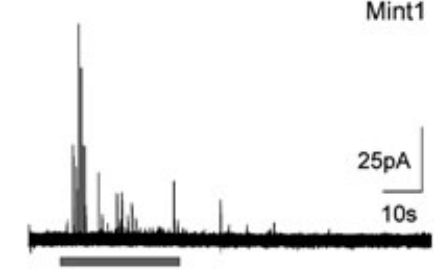

G

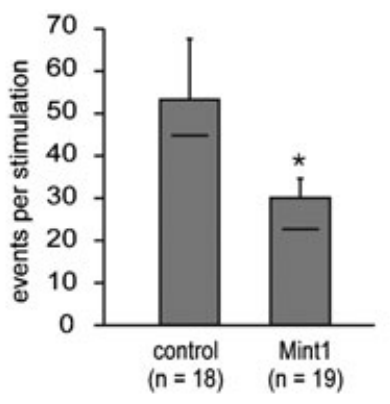

FIG. 5. Mint1 binds differentially to the Munc-18 variants in the presence of syntaxin and exerts an inhibitory influence on exocytosis. (A) Binding of recombinant Munc-18-WT/-D34N/-R39C to GST-Mint1 [Coomassie stained gel, S, supernatant (non-bound); P, pellet (bound)]. GST-Mint1 (3 $\mu$ M) prebound to GSH beads was incubated overnight with $5 \mu \mathrm{M}$ Munc-18-WT/-D34N/-R39C. Immobilized GST-Mint1 precipitates all three Munc-18 proteins with similar efficiency. No binding of Munc-18 proteins to GST alone is observed (lower panels). (B) Binding was performed as in (A), but in the presence of $10 \mu \mathrm{M}$ recombinant syntaxin1a, revealing differences in Mint-binding between the Munc-18 mutants due to competition with syntaxin binding. Note binding of D34N to GST-Mint1 persists in the presence of syntaxin1a to the same extent as without syntaxin1a (compare with A). (C) Quantification of Munc-18 binding to GST-Mint1 in the absence or presence of syntaxin1, as shown in (A and B). The percentage of bound Munc-18 was analysed by quantitative densitometry of the proteins stained with Coomassie blue. Data were collected from four independent experiments. $* P<0.0001$, with one-way analysis of variance for differences between test groups and a TukeyKramer post-test comparing WT $(P<0.01)$ and R39C $(P<0.01)$ binding to Mint1 in the absence and presence of syntaxin. (D) Immunoblots of rat brain homogenate $(15 \mu \mathrm{g} / \mathrm{lane}), \mathrm{PC} 12$ cells $(30 \mu \mathrm{g} / \mathrm{lane})$ and PC12 cells overexpressing Doc $2 \alpha(15 \mu \mathrm{g} / \mathrm{lane})$ were probed with affinity-purified antibody raised against Doc $2 \alpha$ (left panel). The Doc $2 \alpha$ antibody (R93) specifically recognizes in rat brain homogenate and in PC12 cells overexpressing Doc $2 \alpha$ a polypeptide that migrates at a position corresponding to the molecular mass of $\sim 46 \mathrm{kDa}$. In non-transfected PC12 no significant Doc $2 \alpha$ immunosignal was detected. Right panel, GST-Munc18 wild-type protein immobilized on glutathion-Sepharose beads efficiently co-precipitates syntaxin but not Doc $2 \alpha$ from rat brain homogenate. Immunoblots were stained with antibodies against the indicated proteins. (E) Representative amperometric traces from control PC12 cells and cells overexpressing Mint1, stimulated by superfusion with high $\mathrm{K}^{+}$solution (bar). (F) Cumulative events analysis from controls and Mint1-overexpressing cells. Data are normalized to the total number of events recorded in control cells (control, $n=954,18$ cells; Mint1, $n=570$ events, 19 cells). Mint 1 attenuates the exocytotic response by more than $40 \%$ compared with controls. Bar indicates duration of stimulation $(30 \mathrm{~s})$ with high $\mathrm{K}^{+}$. (F) Mean number of LDCV events per cell stimulated by high $\mathrm{K}^{+}$application in control cells $(n=18)$ and Mint1-overexpressing cells $(n=19)$. Values are given as mean \pm SEM. Horizontal lines within the bars indicate the median values of the frequency distributions. $* P<0.05$, Student's $t$-test. 
A

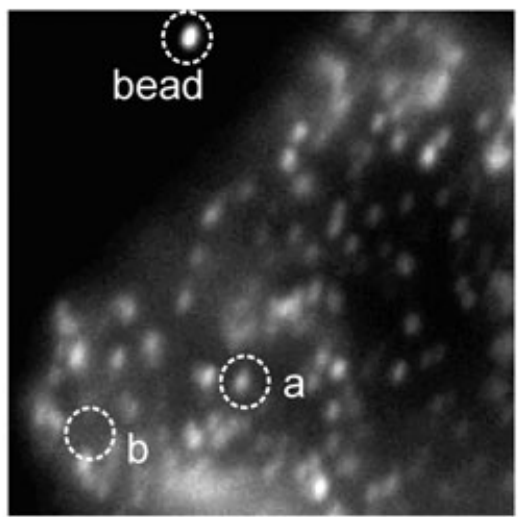

C

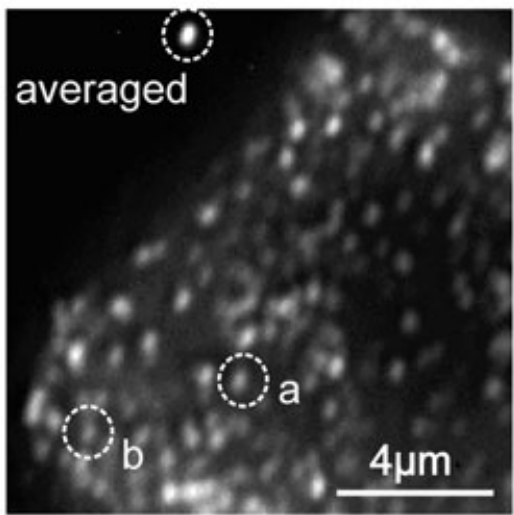

B
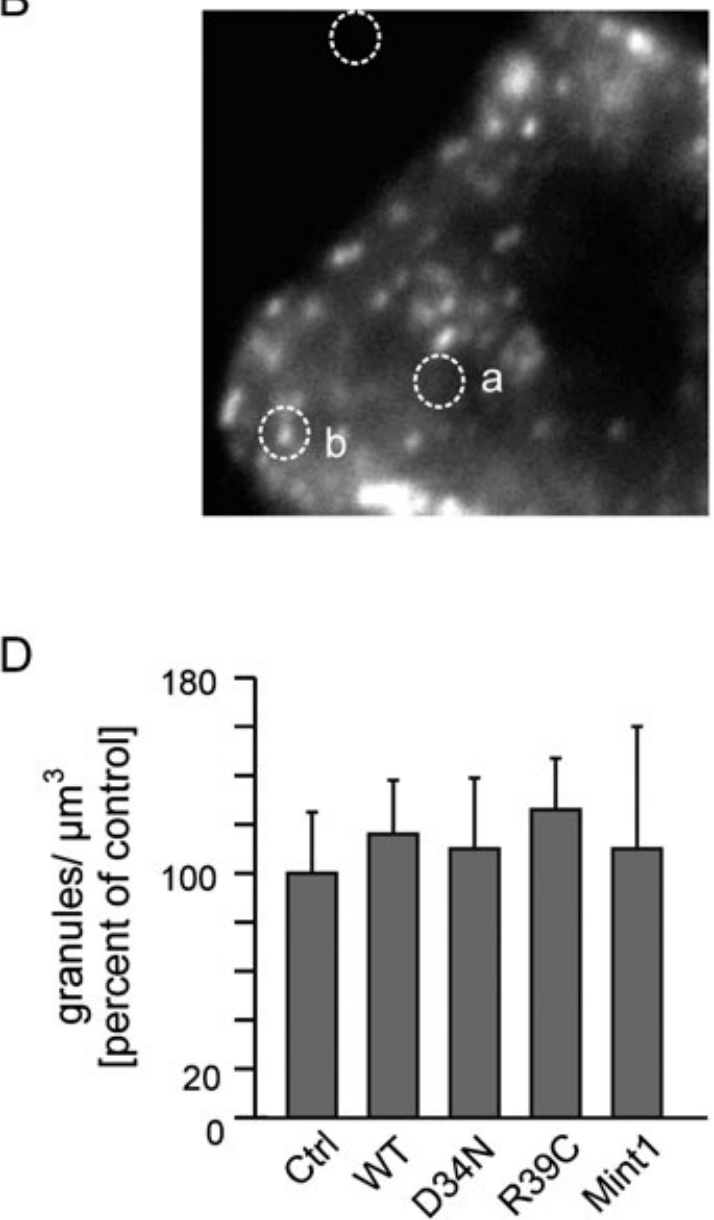

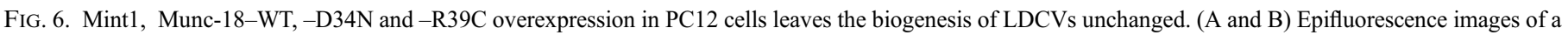

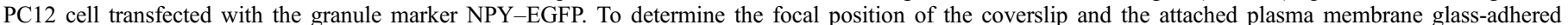

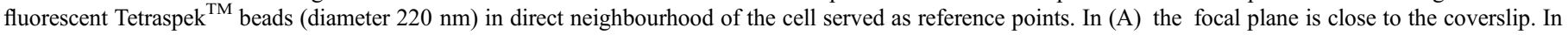

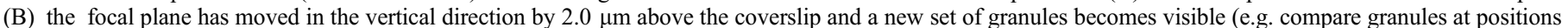

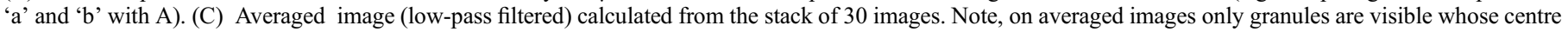

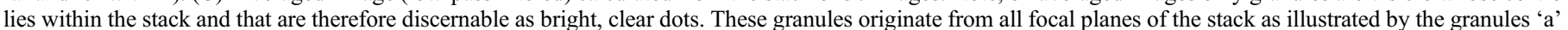

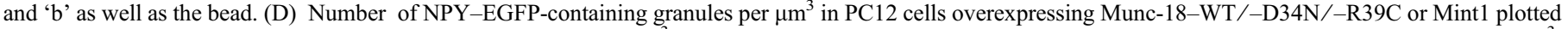

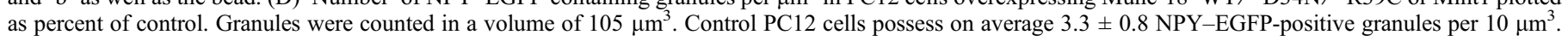

Thus, we conclude that membrane association of Munc-18 largely depends on direct binding to syntaxin, an observation that agrees with the abundance of syntaxin molecules present in PC12 cells providing a sufficient number of binding sites for Munc-18.

\section{Does Munc-18 serve as negative regulator in exocytosis?}

Munc-18 has been proposed to act as a negative regulator in exocytosis by controlling syntaxin's availability for SNARE complexes. Previous studies suggested that syntaxin can exist in at least two different conformations referred to as 'open' (in the core complex) and 'closed' (Hanson et al., 1997; Fernandez et al., 1998; Sutton et al., 1998; Dulubova et al., 1999; Margittai et al., 2003). The latter conformation involves the interaction of the $\mathrm{N}$ - and $\mathrm{C}$ terminal region of syntaxin, and is incompatible with core complex formation but instead allows for binding of Munc-18 (Misura et al., 2000). Therefore, one should expect a reduction of transmitter release upon overexpression of Munc-18. Several lines of evidence are difficult to reconcile with such a scenario in neuroendocrine cells. First, we find that syntaxin 1 exists in a 20 -fold excess over endogenous Munc-18 in PC12 cells. Because both proteins interact with a $1: 1$ stoichiometry (Misura et al., 2000), it is unlikely that Munc-18 controls syntaxin's availability and by this acts as a simple competitor for SNARE complex formation. Second, overexpression of the Munc-18 wild-type protein in PC12 cells does not lead to any inhibition of transmitter release. One might argue that the overexpressed Munc-18 protein binds to a subpopulation of syntaxin1 molecules that is not engaged in exocytosis. We consider this possibility unlikely because the R39C mutant protein attenuates the exocytotic response, indicating that the overexpressed protein intermingles with the pool of syntaxin 1 molecules that is functionally relevant for exocytosis. Third, the inhibitory phenotype of the R39C mutant per se suggests that the Munc-18/syntaxin interaction has a positive role in exocytosis.

Our results agree with previous work by Graham et al. (1997) and Fisher et al. (2001), showing that overexpression of Munc-18 does not attenuate release of human growth hormone from PC12 cells, but are only partially consistent with their reports concerning the effect of the R39C mutant (Fisher et al., 2001). Similar to our results these authors noticed a reduction in exocytotic activity from PC12 cells measured 


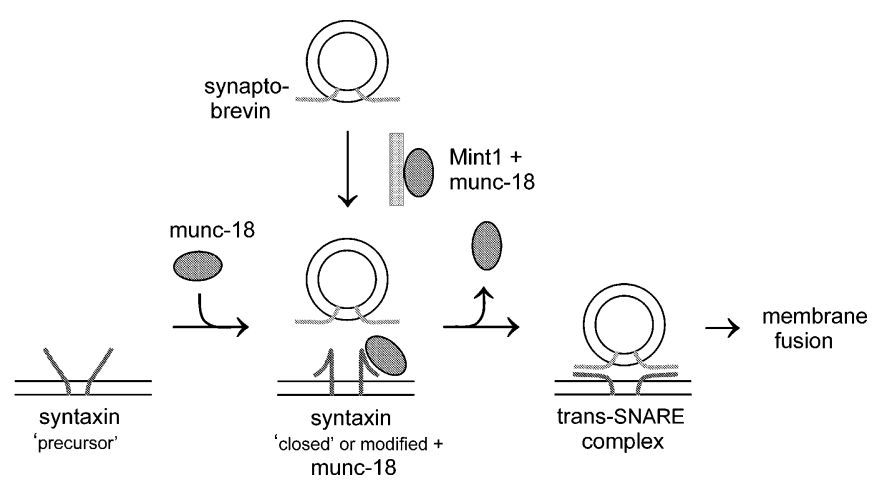

FIG. 7. Model for Munc-18's function in neuroexocytosis. Munc-18 mainly interacts with syntaxin1, while a small fraction of Munc-18 forms the binary Munc-18/Mint1 complex. The trimeric Mint1/Munc-18/syntaxin1 complex (for clarity of illustration not included) likely represents a transitional state between the two binary complexes. The competition between Mint1 and syntaxin1 for Munc-18 binding and the mutual exclusiveness of the Munc18/syntaxin 1 complex and SNARE protein binding to syntaxin makes Munc18 cycle between these two interactions during SNARE complex formation and membrane fusion. Syntaxin, conformationally modified by Munc-18, becomes available for SNARE complex formation. Munc-18 may transiently provide a link between the site of exocytosis and Mint1 functions (e.g. vesicle recruitment) and then fall back into the Munc-18/syntaxin1 complex.

by release of human growth hormone. However, using amperometry in chromaffin cells, Fisher et al. also reported that this observation is due to premature closure of the fusion pores leading to incomplete transmitter discharge with a faster decay of the amperometric signal. Our data demonstrate that PC12 cells overexpressing the R39C mutant protein are capable of performing bona fide membrane fusion. In an extensive analysis of the individual amperometric signal, neither changes of quantal size nor alterations in the kinetic of transmitter discharge are detected (Table 1). Furthermore, foot signals are similar to those in control cells giving us no indication for the control of fusion pore dynamics by Munc-18 in neuroendocrine PC12 cells. In fact, the attenuation of the exocytotic frequency seen upon overexpression of the R39C mutant protein in this study rather suggests that Munc-18 functions upstream of the fusion event.

\section{Munc-18 in exocytosis}

Establishing how the intermolecular reactions of Munc-18 are interrelated is crucial for the understanding of the mechanism of exocytosis. In conjunction with previous studies, our data show that Munc-18 participates in two different complexes that both are functionally relevant for release of neurotransmitter from neuroendocrine cells.

We show that a large number of Munc-18/syntaxin complexes can be established by overexpression of wild-type protein without influencing exocytosis. Still, a perturbation occurs when complex formation is impaired with the R39C mutant protein. Thus, the Munc18 /syntaxin complex is an obligatory intermediate as judged from the $\mathrm{R} 39 \mathrm{C}$ effect, but its formation is not a rate-limiting step for exocytosis of LDCVs as can be concluded from the overexpression of Munc-18WT protein. Previous studies suggested that Munc-18 may have a catalysing function on syntaxin, changing its conformation and by this providing a platform for SNARE complex assembly (Dulubova et al., 1999; Misura et al., 2000). It is conceivable that altered syntaxin binding of the R39C mutant is accompanied with functional impairment of the Munc-18 protein affecting the conformation of the syntaxin molecule.
To address the question of whether Munc-18 has a function in exocytosis beyond its interaction with syntaxin, we studied the role of Mint1 in the secretion process from PC12 cells. Mint1 is a PDZ- and PTB-domain-containing protein that accumulates at synaptic sites (Okamoto et al., 2000), and has been implicated in vesicle transprt and organization of release sites (Butz et al., 1998; Setou et al., 2000). Moreover, Biederer \& Sudhof (2000) showed that association of Munc-18 to Mint1 enhances Mintl's interaction with CASK. CASK is a membrane-associated guanylate kinase domain protein (MAGUK) that binds to the cytoplasmic tail of the presynaptic adhesion molecule neurexin and that may govern F-actin nucleation at release sites (Hata et al., 1996; Biederer \& Südhof, 2001). Thus, the molecular properties of Mint-mediated mechanisms appear to be well suited to influence the exocytotic response. In fact, deletion of Mint1 has been found to increase the release probability at inhibitory synapses (Ho et al., 2003). We show that overexpression of Mint1 inhibits LDCV exocytosis in neuroendocrine PC12 cells. Our biochemical data provide strong evidence that syntaxin 1 and Mint1 compete for Munc18 binding positioning Munc-18 at the functional interface between syntaxin-mediated mechanisms and a Mint-mediated control of the exocytotic pathway. In order to unmask 'non-syntaxin'-related functions of Munc-18, we took advantage of the D34N mutation that abolishes any binding to syntaxin. This mutant protein has a stimulatory effect on the exocytotic response and accumulates in the cytosol where the Mint1 protein is preferentially found. Thus, it is conceivable that increased binding of Mint1 by the D34N protein is responsible for the stimulatory action of the mutant protein producing a disinhibition by sequestering Mint1.

Taken together, the data suggest that Munc-18 participates in at least two complexes that localize to the plasma membrane and to the cytosol, respectively, and that likely govern functionally distinct mechanisms. In the presence of a large amount of 'free' syntaxin, however, the high-affinity interaction between syntaxin and Munc-18 (dissociation constant $\sim 5 \mathrm{nM}$, Pevsner et al., 1994b) appears to outrun the competing interaction with Mint1, limiting the increase in cytosolic Munc-18 (see Fig. 1D). Such a scenario can explain why a significant activation of the Mint-pathway is prevented upon overexpression of the wild-type protein. Thus, changes in cytosolic levels of Munc-18 controlled by the high-affinity interaction with syntaxin may serve as an important regulatory event in the exocytotic pathway.

How can our findings be integrated with other studies on Munc-18 function in LDCV exocytosis? Previous studies by Dulubova et al. (1999) found an inhibition of secretion from PC12 cells by overexpression of the cytoplasmic region of syntaxin1. This effect is abolished when a syntaxin mutant (L165A/E166A) is used that preferentially adopts the 'open' conformation. Consequently, inhibition could be due to sequestering of Munc-18 from the exocytotic machinery, an observation that agrees well with our finding that an increase of cytosolic Munc-18 may lead to more frequent interactions with the Mint 1 protein mediating the stimulatory effect on exocytosis. Interestingly the same syntaxin mutant is able to compensate for a lack of another synaptic protein, Munc-13, that has been implicated in priming of secretory organelles (Richmond et al., 2001) but fails to rescue the severe paralysis of the Munc-18 null mutant (Weimer et al., 2003). The latter observation is consistent with the view of a dual role of Munc-18 in exocytosis. Furthermore, overexpression of Munc-18 in bovine chromaffin cells with the Semliki Forest virus system increases the exocytotic response (Voets et al., 2001). Provided that levels of overexpressed Munc-18 protein are sufficient to saturate the endogenous population of syntaxin molecules, the observed increase in exocytosis may also be due to more frequent interactions between Munc-18 and the Mint1 protein. 
We propose a scenario in which Munc-18 serves as a dynamic and precise link between the fusion machinery (via syntaxin 1 binding) and proteins activating presynaptic superstructures (via Mint1 binding), with Munc-18 switching from one interaction to the other during exocytosis (Fig. 7). In fact, such a switch can be promoted by PKCdependent phosphorylation of Munc-18 that has been shown to occur preferentially during calcium-dependent exocytosis in rat brain nerve terminals (de Vries et al., 2000). The PKC-catalysed phosphorylation of Munc-18 prevents the high-affinity interaction with syntaxin (Fujita et al., 1996). Conformationally modified syntaxin may now become available to form protein complexes such as the core complex in order to drive vesicle fusion. In parallel, Munc-18 is free to bind Mint1. It is conceivable that such a mechanism may ensure the replenishment of new secretory organelles to sites at the plasma membrane where exocytosis just occurred. This may contribute to the observed lack of docked granules in the absence of the Munc18/unc18 protein (Voets et al., 2001; Weimer et al., 2003). Indeed, transient 'uncaging' of Munc-18 could provide a localized signal for membrane trafficking reactions. The Munc-18/syntaxin complex would in this scenario define such exocytosis-competent plasma membrane areas and the precision of the interaction would guarantee for efficient and correct delivery of secretory organelles.

\section{Acknowledgements}

We thank D. Ferrari for helpful comments on the manuscript. We are grateful to S. Pabst for providing tag-free syntaxin1a and to Marcin Barszczewski for providing cells for the NPY-EGFP experiment. We also thank D. Diezmann for skilful technical assistance with antibodies. This work was supported by the DFG (SFB 406) to D.B. and by the Leibniz Award of the DFG to R.J.

\section{Abbreviations}

LDCV, large dense core vesicles; NPY, neuropeptide Y; PBS, phosphatebuffered saline; PCR, polymerase chain reaction; SDS-PAGE, sodium dodecyl sulphate-polyacrylamide gel electrophoresis.

\section{References}

Albillos, A., Dernick, G., Horstmann, H., Almers, W., Alvarez de Toledo, G. \& Lindau, M. (1997) The exocytotic event in chromaffin cells revealed by patch amperometry. Nature, 389, 509-512.

Alvarez de Toledo, G., Fernandez-Chacon, R. \& Fernandez, J.M. (1993) Release of secretory products during transient vesicle fusion. Nature, 363, $554-558$.

Atlas, D. (2001) Functional and physical coupling of voltage-sensitive calcium channels with exocytotic proteins: ramifications for the secretion mechanism. J. Neurochem., 77, 972-985.

Barnstable, C.J., Hofstein, R. \& Akagawa, K. (1985) A marker of early amacrine cell development in rat retina. Brain. Res., 352, 286-290.

Biederer, T. \& Sudhof, T.C. (2000) Mints as adaptors. Direct binding to neurexins and recruitment of Munc-18. J. Biol. Chem., 275, 39803-39806.

Biederer, T. \& Sudhof, T.C. (2001) CASK and protein 4.1 support F-actin nucleation on neurexins. J. Biol. Chem., 276, 47869-47876.

Borg, J.P., Straight, S.W., Kaech, S.M., de Taddeo-Borg, M., Kroon, D.E., Karnak, D., Turner, R.S., Kim, S.K. \& Margolis, B. (1998) Identification of an evolutionarily conserved heterotrimeric protein complex involved in protein targeting. J. Biol. Chem., 273, 31633-31636.

Brunger, A.T. (2001) Structural insights into the molecular mechanism of calcium-dependent vesicle-membrane fusion. Curr. Opin. Struct. Biol., 11, 163-173.

Bruns, D. (1998) Serotonin transport in cultured leech neurons. Methods Enzymol., 296, 593-607.

Bruns, D., Riedel, D., Klingauf, J. \& Jahn, R. (2000) Quantal release of serotonin. Neuron, 28, 205-220.

Butz, S., Okamoto, M. \& Sudhof, T.C. (1998) A tripartite protein complex with the potential to couple synaptic vesicle exocytosis to cell adhesion in brain. Cell, 94, 773-782.
Carr, C.M., Grote, E., Munson, M., Hughson, F.M. \& Novick, P.J. (1999) Sec1p binds to SNARE complexes and concentrates at sites of secretion. J. Cell. Biol., 146, 333-344.

Chen, Y.A. \& Scheller, R.H. (2001) SNARE-mediated membrane fusion. Nat. Rev. Mol. Cell. Biol., 2, 98-106.

Chow, R.H., von Ruden, L. \& Neher, E. (1992) Delay in vesicle fusion revealed by electrochemical monitoring of single secretory events in adrenal chromaffin cells. Nature, 356, 60-63.

Dulubova, I., Sugita, S., Hill, S., Hosaka, M., Fernandez, I., Sudhof, T.C. \& Rizo, J. (1999) A conformational switch in syntaxin during exocytosis: role of munc18. EMBO J., 18, 4372-4382.

Duncan, R.R., Apps, D.K., Learmonth, M.P., Shipston, M.J. \& Chow, R.H. (2000) Is double C2 protein (DOC2) expressed in bovine adrenal medulla? A commercial anti-DOC2 monoclonal antibody recognizes a major bovine mitochondrial antigen. Biochem. J., 351, 33-37.

Fernandez, I., Ubach, J., Dulubova, I., Zhang, X., Sudhof, T.C. \& Rizo, J. (1998) Three-dimensional structure of an evolutionarily conserved N-terminal domain of syntaxin 1A. Cell, 18, 841-849.

Fisher, R.J., Pevsner, J. \& Burgoyne, R.D. (2001) Control of fusion pore dynamics during exocytosis by Munc-18. Science, 291, 875-878.

Fujita, Y., Sasaki, T., Fukui, K., Kotani, H., Kimura, T., Hata, Y., Sudhof, T.C., Scheller, R.H. \& Takai, Y. (1996) Phosphorylation of Munc-18/ $\mathrm{n}-\mathrm{Sec} 1 / \mathrm{rbSec} 1$ by protein kinase $\mathrm{C}$ : its implication in regulating the interaction of Munc-18/n-Sec1/rbSec1 with syntaxin. J. Biol. Chem., 271, 72657268.

Gallwitz, D. \& Jahn, R. (2003) The riddle of the Sec1/Munc-18 proteins - new twists added to their interactions with SNAREs. Trends Biochem. Sci., 28, $113-116$.

Garcia, E.P., Gatti, E., Butler, M., Burton, J. \& De Camilli, P. (1994) A rat brain Sec1 homologue related to Rop and UNC18 interacts with syntaxin. Proc. Natl. Acad. Sci. USA, 91, 2003-2007.

Garcia, E.P., McPherson, P.S., Chilcote, T.J., Takei, K. \& De Camilli, P. (1995) $\mathrm{rbSec} 1 \mathrm{~A}$ and B colocalize with syntaxin 1 and SNAP-25 throughout the axon, but are not in a stable complex with syntaxin. J. Cell Biol., 129, 105-120.

Graham, M.E., Sudlow, A.W. \& Burgoyne, R.D. (1997) Evidence against an acute inhibitory role of nSec-1 (munc-18) in late steps of regulated exocytosis in chromaffin and PC12 cells. J. Neurochem., 69, 2369-2377.

Greene, L.A., Aletta, J.M., Rukenstein, A. \& Green, S.H. (1987) PC12 pheochromocytoma cells: culture, nerve growth factor treatment, and experimental exploitation. Meth. Enzymol., 147, 207-216.

Greene, L.A. \& Tischler, A.S. (1976) Establishment of a noradrenergic clonal line of rat adrenal pheochromocytoma cells which respond to nerve growth factor. Proc. Natl. Acad. Sci. USA, 73, 2424-2428.

Grote, E., Carr, C.M. \& Novick, P.J. (2000) Ordering the final events in yeast exocytosis. J. Cell Biol., 151, 439-452.

Hanson, P.I., Heuser, J.E. \& Jahn, R. (1997) Neurotransmitter release - four years of SNARE complexes. Curr. Opin. Neurobiol., 7, 310-315.

Harrison, S.D., Broadie, K., van de Goor, J. \& Rubin, G.M. (1994) Mutations in the Drosophila Rop gene suggest a function in general secretion and synaptic transmission. Neuron, 13, 555-566.

Hata, Y., Butz, S. \& Sudhof, T.C. (1996) CASK: a novel dlg/PSD95 homolog with an $\mathrm{N}$-terminal calmodulin-dependent protein kinase domain identified by interaction with neurexins. J. Neurosci., 16, 2488-2494.

Hata, Y., Slaughter, C.A. \& Sudhof, T.C. (1993) Synaptic vesicle fusion complex contains unc-18 homologue bound to syntaxin. Nature, 366, 347-351.

Hayashi, T., Yamasaki, S., Nauenburg, S., Binz, T. \& Niemann, H. (1995) Disassembly of the econstituted synaptic vesicle membrane fusion complex in vitro. EMBO J., 14, 2317-2325.

Higuchi, R., Krummel, B. \& Saiki, R.K. (1988) A general method of in vitro preparation and specific mutagenesis of DNA fragments: study of protein and DNA interactions. Nucleic Acids Res., 16, 7351-7367.

Ho, A., Morishita, W., Hammer, R.E., Malenka, R.C. \& Sudhof, T.C. (2003) A role for Mints in transmitter release: Mint 1 knockout mice exhibit impaired GABAergic synaptic transmission. Proc. Natl Acad. Sci. USA, 100, 14091414.

Holroyd, P., Lang, T., Wenzel, D., De Camilli, P. \& Jahn, R. (2002) Imaging direct, dynamin-dependent recapture of fusing secretory granules on plasma membrane lawns from PC12 cells. Proc. Natl. Acad. Sci. USA, 99, 1680616811 .

Jahn, R. (2000) Sec1/Munc-18 proteins: mediators of membrane fusion moving to center stage. Neuron, 27, 201-204.

Lang, T., Bruns, D., Wenzel, D., Riedel, D., Holroyd, P., Thiele, C. \& Jahn, R. (2001) SNAREs are concentrated in cholesterol-dependent clusters that define docking and fusion sites for exocytosis. EMBO J., 20, 2202-2213. 
Lang, T., Wacker, I., Steyer, J., Kaether, C., Wunderlich, I., Soldati, T., Gerdes, H.H. \& Almers, W. (1997) $\mathrm{Ca}^{2+}$-triggered peptide secretion in single cells imaged with green fluorescent protein and evanescent-wave microscopy. Neuron, 18, 857-863.

Lang, T., Wacker, I., Wunderlich, I., Rohrbach, A., Giese, G., Soldati, T. \& Almers, W. (2000) Role of actin cortex in the subplasmalemmal transport of secretory granules in PC-12 cells. Biophys. J., 78, 2863-2877.

Majlof, L. \& Forsgren, P.O. (1993) Confocal microscopy: important considerations for accurate imaging. Meth. Cell Biol., 38, 79-95.

Margittai, M., Widengren, J., Schweinberger, E., Schroder, G.F., Felekyan, S., Haustein, E., Konig, M., Fasshauer, D., Grubmuller, H., Jahn, R. \& Seidel, C.A. (2003) Single-molecule fluorescence resonance energy transfer reveals a dynamic equilibrium between closed and open conformations of syntaxin 1. Proc. Natl. Acad. Sci. USA, 100, 15516-15521.

Misura, K.M., Scheller, R.H. \& Weis, W.I. (2000) Three-dimensional structure of the neuronal-Sec1-syntaxin 1a complex. Nature, 404, 355-362.

Okamoto, M. \& Sudhof, T.C. (1997) Mints, Munc-18-interacting proteins in synaptic vesicle exocytosis. J. Biol. Chem., 272, 31459-31464.

Okamoto, M., Matsuyama, T. \& Sugita, M. (2000) Ultrastructural localization of mintl at synapses in mouse hippocampus. Eur. J. Neurosci., 12, $3067-$ 3072.

Peng, R. \& Gallwitz, D. (2002) Sly1 protein bound to Golgi syntaxin Sed5p allows assembly and contributes to specificity of SNARE fusion complexes. J. Cell Biol., 157, 645-655.

Perez-Branguli, F., Muhaisen, A. \& Blasi, J. (2002) Munc 18a binding to syntaxin $1 \mathrm{~A}$ and $1 \mathrm{~B}$ isoforms defines its localization at the plasma membrane and blocks SNARE assembly in a three-hybrid system assay. Mol. Cell Neurosci., 20, 169-180.

Pevsner, J., Hsu, S.C., Braun, J.E., Calakos, N., Ting, A.E., Bennett, M.K. \& Scheller, R.H. (1994b) Specificity and regulation of a synaptic vesicle docking complex. Neuron, 13, 353-361.

Pevsner, J., Hsu, S.C. \& Scheller, R.H. (1994a) n-Sec1: a neural-specific syntaxin-binding protein. Proc. Natl. Acad. Sci. USA, 91, 1445-1449.

Richmond, J.E., Weimer, R.M. \& Jorgensen, E.M. (2001) An open form of syntaxin bypasses the requirement for UNC-13 in vesicle priming. Nature, 412, 338-341.

Rizo, J. \& Sudhof, T.C. (2002) Snares and Muncl8 in synaptic vesicle fusion. Nat. Rev. Neurosci., 3, 641-653.
Schulze, K.L., Littleton, J.T., Salzberg, A., Halachmi, N., Stern, M., Lev, Z. \& Bellen, H.J. (1994) rop, a Drosophila homolog of yeast Sec1 and vertebrate $\mathrm{n}$-Sec1/Munc-18 proteins, is a negative regulator of neurotransmitter release in vivo. Neuron, 13, 1099-1108.

Setou, M., Nakagawa, T., Seog, D.H. \& Hirokawa, N. (2000) Kinesin superfamily motor protein KIF17 and mLin-10 in NMDA receptorcontaining vesicle transport. Science, 288, 1796-1802.

Sutton, R.B., Fasshauer, D., Jahn, R. \& Brunger, A.T. (1998) Crystal structure of a SNARE complex involved in synaptic exocytosis at 2.4 A resolution. Nature, 395, 347-353.

Tall, G.G., Hama, H., DeWald, D.B. \& Horazdovsky, B.F. (1999) The phosphatidylinositol 3-phosphate binding protein Vac1p interacts with a Rab GTPase and a Seclp homologue to facilitate vesicle-mediated vacuolar protein sorting. Mol. Biol. Cell, 10, 1873-1889.

Toonen, R.F. \& Verhage, M. (2003) Vesicle trafficking: pleasure and pain from SM genes. Trends Cell Biol., 13, 177-186.

Verhage, M., de Vries, K.J., Roshol, H., Burbach, J.P., Gispen, W.H. \& Sudhof, T.C. (1997) DOC2 proteins in rat brain: complementary distribution and proposed function as vesicular adapter proteins in early stages of secretion. Neuron, 18, 453-461.

Verhage, M., Maia, A.S., Plomp, J.J., Brussaard, A.B., Heeroma, J.H., Vermeer, H., Toonen, R.F., Hammer, R.E., van den Berg, T.K., Missler, M., Geuze, H.J. \& Sudhof, T.C. (2000) Synaptic assembly of the brain in the absence of neurotransmitter secretion. Science, 287, 864-869.

Voets, T., Toonen, R.F., Brian, E.C., de Wit, H., Moser, T., Rettig, J., Sudhof, T.C., Neher, E. \& Verhage, M. (2001) Munc-18-1 promotes large dense-core vesicle docking. Neuron, 31, 581-591.

de Vries, K.J., Geijtenbeek, A., Brian, E.C., de Graan, P.N., Ghijsen, W.E. \& Verhage, M. (2000) Dynamics of Munc-18-1 phosphorylation/dephosphorylation in rat brain nerve terminals. Eur. J. Neurosci., 12, 385-390.

Weimer, R.M., Richmond, J.E., Davis, W.S., Hadwiger, G., Nonet, M.L. \& Jorgensen, E.M. (2003) Defects in synaptic vesicle docking in unc-18 mutants. Nat. Neurosci., 6, 1023-1030.

Wu, M.N., Littleton, J.T., Bhat, M.A., Prokop, A. \& Bellen, H.J. (1998) ROP, the Drosophila Sec1 homolog, interacts with syntaxin and regulates neurotransmitter release in a dosage-dependent manner. EMBO J., 17, 127-139.

Yang, B., Steegmaier, M., Gonzalez, L.C., Jr. \& Scheller, R.H. (2000) nSecl binds a closed conformation of syntaxinlA. J. Cell Biol., 148, 247-252. 